\title{
Multimodality Molecular Imaging of Tumor Angiogenesis
}

\author{
Weibo Cai ${ }^{1,2}$ and Xiaoyuan Chen $^{1}$ \\ ${ }^{1}$ Molecular Imaging Program at Stanford, Department of Radiology, Biophysics, and Bio-X Program, School of Medicine, Stanford \\ University, Stanford, California; and ${ }^{2}$ Department of Radiology and Medical Physics, School of Medicine and Public Health, \\ University of Wisconsin-Madison, Madison, Wisconsin
}

\begin{abstract}
Molecular imaging is a key component of 21 st-century cancer management. The vascular endothelial growth factor (VEGF)/ VEGF receptor signaling pathway and integrin $\alpha_{v} \beta_{3}$, a cell adhesion molecule, play pivotal roles in regulating tumor angiogenesis, the growth of new blood vessels. This review summarizes the current status of tumor angiogenesis imaging with SPECT, PET, molecular MRI, targeted ultrasound, and optical techniques. For integrin $\alpha_{v} \beta_{3}$ imaging, only nanoparticle-based probes, which truly target the tumor vasculature rather than tumor cells because of poor extravasation, are discussed. Once improvements in the in vivo stability, tumor-targeting efficacy, and pharmacokinetics of tumor angiogenesis imaging probes are made, translation to clinical applications will be critical for the maximum benefit of these novel agents. The future of tumor angiogenesis imaging lies in multimodality and nanoparticlebased approaches, imaging of protein-protein interactions, and quantitative molecular imaging. Combinations of multiple modalities can yield complementary information and offer synergistic advantages over any modality alone. Nanoparticles, possessing multifunctionality and enormous flexibility, can allow for the integration of therapeutic components, targeting ligands, and multimodality imaging labels into one entity, termed "nanomedicine," for which the ideal target is tumor neovasculature. Quantitative imaging of tumor angiogenesis and protein-protein interactions that modulate angiogenesis will lead to more robust and effective monitoring of personalized molecular cancer therapy. Multidisciplinary approaches and cooperative efforts from many individuals, institutions, industries, and organizations are needed to quickly translate multimodality tumor angiogenesis imaging into multiple facets of cancer management. Not limited to cancer, these novel agents can also have broad applications for many other angiogenesis-related diseases.
\end{abstract}

\footnotetext{
Received Aug. 1, 2007; revision accepted Oct. 1, 2007.

For correspondence or reprints contact either of the following:

Xiaoyuan Chen, Molecular Imaging Program at Stanford, Department of

Radiology and Bio-X Program, School of Medicine, Stanford University, 1201

Welch Rd., P095, Stanford, CA 94305-5484.

E-mail: shawchen@stanford.edu

Weibo Cai, Departments of Radiology and Medical Physics, School of

Medicine and Public Health, University of Wisconsin-Madison, K4/628

Clinical Science Center, 600 Highland Ave., Madison, WI 53792-3252.

E-mail: wcai@uwhealth.org

COPYRIGHT @ 2008 by the Society of Nuclear Medicine, Inc.
}

Key Words: tumor angiogenesis; vascular endothelial growth factor; vascular endothelial growth factor receptor; integrin $\alpha_{\mathrm{v}} \beta_{3}$; multimodality molecular imaging

J Nucl Med 2008; 49:113S-128S

DOI: 10.2967/jnumed.107.045922

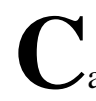

ancer is the second leading cause of death in the United States (http://www.cdc.gov). In 2007, about 1,444,920 new cancer cases were expected to be diagnosed, and about 559,650 Americans were expected to die of cancer-more than 1,500 people per day (http://www.cancer.org). The National Institutes of Health estimated an overall cost of $\$ 206.3$ billion as a result of cancer (http://www.nih.gov). One of the key requirements during tumor development is angiogenesis, the formation of new blood vessels, without which a tumor cannot grow beyond a few millimeters in diameter $(1,2)$. Tumor angiogenesis is regulated by a variety of proteins, such as growth factors/growth factor receptors, G-protein-coupled receptors for angiogenesismodulating proteins, several endogenous angiogenesis inhibitors, and integrins (2-4). The fact that tumor progression is dependent on angiogenesis has inspired scientists to search for antiangiogenic molecules and to design antiangiogenic strategies for cancer treatment and the prevention of cancer recurrence or metastasis (5-7).

Many traditional medical imaging techniques, such as CT, MRI, and ultrasound, have been routinely used to monitor the therapeutic effects of cancer intervention $(8,9)$. The field of molecular imaging, recently defined by the Society of Nuclear Medicine as "the visualization, characterization, and measurement of biological processes at the molecular and cellular levels in humans and other living systems" (10), has flourished over the last decade. In general, molecular imaging modalities include molecular MRI (mMRI), magnetic resonance spectroscopy, optical bioluminescence imaging, optical fluorescence imaging, targeted ultrasound, SPECT, and PET (11). Many hybrid systems that combine 2 or more of these imaging modalities are also commercially available, and certain others are under active development (12-14). Noninvasive imaging of 
tumor angiogenesis can allow for much earlier diagnosis and better prognosis, which will eventually lead to personalized molecular medicine $(15,16)$. In this review, we summarize the progress to date on multimodality molecular imaging of tumor angiogenesis, focusing on the vascular endothelial growth factor (VEGF)/VEGF receptor (VEGFR) signaling pathway and integrin $\alpha_{\mathrm{v}} \beta_{3}$.

\section{VEGF/VEGFRS}

The VEGF/VEGFR signaling pathway plays a pivotal role in both normal vasculature development and many disease processes $(3,17)$. The VEGF family is composed of 7 members with a common VEGF homology domain: VEGF-A, VEGF-B, VEGF-C, VEGF-D, VEGF-E, VEGF-F, and placenta growth factor $(18,19)$. VEGF-A is a homodimeric, disulfide-bound glycoprotein existing in several isoforms with different numbers of amino acid residues, such as $\mathrm{VEGF}_{121}$ and $\mathrm{VEGF}_{165}$. Besides the difference in molecular weights, these isoforms also differ in their biologic properties, in particular, the ability to bind to cell surface heparin sulfate proteoglycans (19).

The angiogenic actions of VEGF are mainly mediated by 2 endothelium-specific receptor tyrosine kinases, VEGFR-1 (Flt-1/FLT-1) and VEGFR-2 (Flk-1/KDR) (20). VEGFR-1 is critical for physiologic and developmental angiogenesis, and its function varies with the stages of development, the states of physiologic and pathologic conditions, and the cell types in which it is expressed $(17,19)$. VEGFR-2 is the major mediator of the mitogenic, angiogenic, and permeability-enhancing effects of VEGF. VEGF/VEGFR overexpression has been implicated as a poor prognostic marker in many clinical studies (19). Agents that prevent VEGF from binding to its receptors (21), antibodies that block VEGFR-2 (22,23), and small molecules that inhibit the kinase activity of VEGFR-2, thereby terminating the signaling cascades (24-26), are all currently under active development. The pivotal role of the VEGF/VEGFR signaling pathway in cancer is underscored by the approval of the humanized anti-VEGF monoclonal antibody bevacizumab (Avastin; Genentech) for the first-line treatment of cancer patients (27-29). VEGF/VEGFR-targeted molecular imaging can serve as a new paradigm for assessing the efficacy of antiangiogenic cancer therapy, improving cancer management, and elucidating the role and modulation of VEGF/VEGFR signaling during cancer development and intervention.

\section{RADIONUCLIDE-BASED IMAGING OF VEGF/VEGFR EXPRESSION}

Radionuclide-based imaging has been routinely used in clinics over the last decade. Because of the wider availability of $\gamma$-cameras and SPECT scanners in the past (30), VEGFR imaging was achieved with SPECT earlier than with PET. Several radioisotopes, such as ${ }^{123} \mathrm{I},{ }^{111} \mathrm{In},{ }^{99 \mathrm{~m}} \mathrm{Tc}$,
${ }^{64} \mathrm{Cu}$, and ${ }^{89} \mathrm{Zr}$, have been used for either SPECT or PET applications.

\section{SPECT of VEGFRs}

To explore the possibility of VEGFR scintigraphy of primary tumors and their metastases, the properties of binding of ${ }^{123} \mathrm{I}_{-} \mathrm{VEGF}_{165}$ and ${ }^{123} \mathrm{I}_{-} \mathrm{VEGF}_{121}$ to human umbilical vein endothelial cells, several human tumor cell lines, and a variety of primary human tumors were evaluated (31). Besides human umbilical vein endothelial cells, some tumor cells were also found to express large numbers of VEGFRs in that study. ${ }^{123} \mathrm{I}_{-} \mathrm{VEGF}_{165}$ was then evaluated for tumor localization in gastrointestinal cancer patients (32). However, the primary and metastatic lesions were identified only in some patients. In another study, the biodistribution, safety, and absorbed dose of ${ }^{123}{ }^{2}$-VEGF $_{165}$ were investigated in 9 patients with pancreatic carcinomas (33). Although the majority of the primary pancreatic tumors and their metastases were visualized on ${ }^{123}$ I-VEGF $_{165}$ scans (Fig. 1A), the organ with the highest absorbed dose was the thyroid because of severe deiodination. Another report also suggested that ${ }^{123} \mathrm{I}_{-} \mathrm{VEGF}_{165}$, despite high receptor-binding affinity, showed poor tumor-to-background ratios in tumorbearing mice because of low metabolic stability (34). Recently, ${ }^{125} \mathrm{I}_{-} \mathrm{VEGF}_{121}$ and ${ }^{125} \mathrm{I}_{-} \mathrm{VEGF}_{165}$ were used for biodistribution and autoradiography studies (35). As with most other radioiodinated tracers, prominent activity accumulation in the stomach was observed because of deiodination. Interestingly, ${ }^{125} \mathrm{I}_{-} \mathrm{VEGF}_{121}$ accumulation in tumors decreased with increasing tumor volume, suggesting that small tumors have higher VEGFR expression than large tumors. It was also found that ${ }^{125} \mathrm{I}^{-V_{E G F}} \mathrm{FG5}_{165}$ uptake was higher than that of ${ }^{125} \mathrm{I}_{-} \mathrm{VEGF}_{121}$ in some organs (such as the kidneys, heart, and lungs) but lower in many other organs (35). The reason for such differences in patterns of accumulation between the 2 tracers remains unclear.

Besides radioiodine, $\mathrm{VEGF}_{121}$ has also been labeled with ${ }^{99 \mathrm{~m}} \mathrm{Tc}(36,37)$. In a $4 \mathrm{~T} 1$ murine mammary carcinoma model, the tumor uptake of ${ }^{99 \mathrm{~m} T c-V_{E G F}}{ }_{121}$, measured as percentage injected dose per gram of tissue $(\% \mathrm{ID} / \mathrm{g})$, was found to be about $3 \% \mathrm{ID} / \mathrm{g}$ (Fig. 1B). It was suggested that ${ }^{99} \mathrm{mc}^{\mathrm{T}}-\mathrm{VEGF}_{121}$, stable for about $1 \mathrm{~h}$ in vivo, can be used to image mouse tumor neovasculature in lesions as small as several millimeters in soft tissue. Recently, this tracer was also applied to imaging of the tumor vasculature before and after various types of chemotherapy (38).

A recombinant protein composed of $\mathrm{VEGF}_{165}$ fused through a flexible polypeptide linker, (GGGGS) $)_{3}$, to the n-lobe of human transferrin (hnTf-VEGF) was used for angiogenesis imaging (39). The molecular masses of hnTfVEGF are 65 and $130 \mathrm{kDa}$ for the monomeric and dimeric forms, respectively. ${ }^{111}$ In-hnTf-VEGF accumulated in U87MG human glioblastoma tumors at $6.7 \% \mathrm{ID} / \mathrm{g}$ at $72 \mathrm{~h}$ after injection. The tumor uptake of ${ }^{111} \mathrm{In}-\mathrm{hnTf}-\mathrm{VEGF}$ decreased when it was coinjected with a 100-fold excess of VEGF but not apotransferrin (Fig. 1C). This fusion 


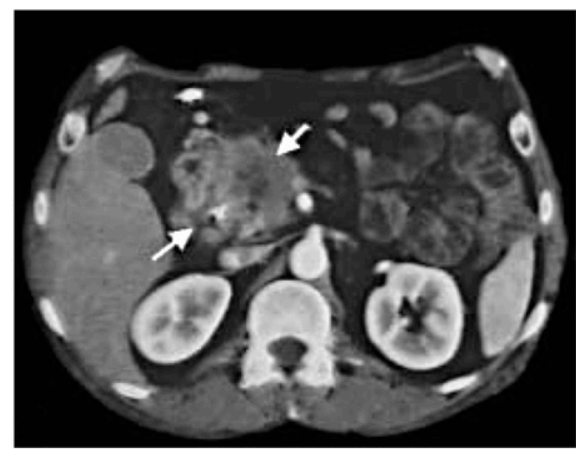

CT

B

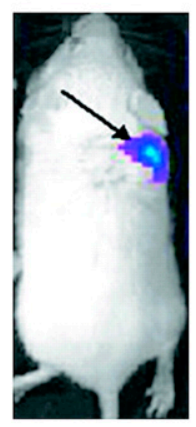

BLI

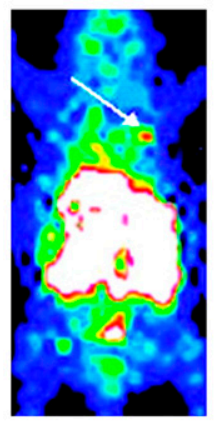

${ }_{99 m}{ }^{2}-V E G F_{121}$

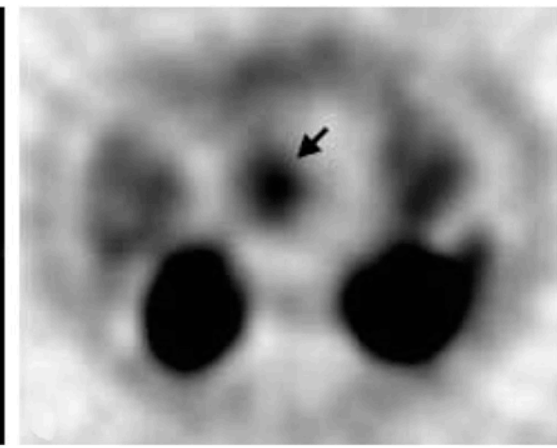

123|-VEGF 165

C

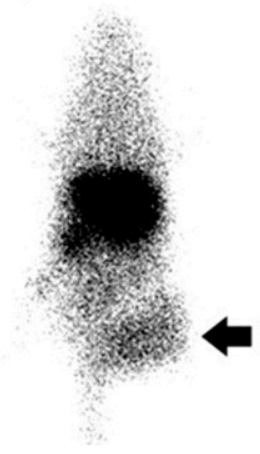

${ }^{111}$ In-hnTf-VEGF

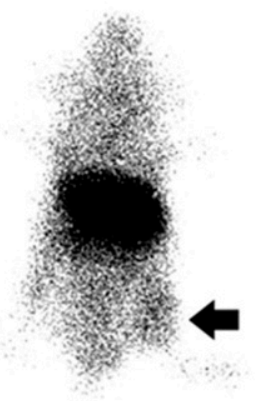

Block
FIGURE 1. SPECT of VEGFR expression. (A) Transverse CT image of pancreatic adenocarcinoma patient (left) and transverse SPECT image of same patient at $1.5 \mathrm{~h}$ after injection of ${ }^{123}$ I-VEGF ${ }_{165}$ (right). (B) Bioluminescence imaging (BLI; after injection of $\mathrm{D}$-luciferin) and SPECT (after injection of ${ }^{99 m T c-V E G F}$ 121 ) images of tumor-bearing mouse. Tumor cells were transfected with firefly luciferase. (C) Posterior whole-body images of tumor-bearing mouse at $48 \mathrm{~h}$ after injection of ${ }^{111} \mathrm{In}-\mathrm{hnTf}-\mathrm{VEGF}$ and after coinjection of 100 -fold excess of unlabeled apotransferrin (Block). Arrows in all images indicate tumors. (Adapted from $(33,36,39)$.) protein, hnTf-VEGF, represents a new class of proteins that can be labeled with ${ }^{111}$ In without the need to introduce metal chelators.

All of the reports mentioned so far used radiolabeled VEGF isoforms for SPECT of VEGFR expression. Although the VEGF isoforms used in these studies all exist in nature and should have very high binding affinity and specificity for VEGFRs, much research effort is still needed to improve the in vivo stability, target affinity and specificity, and pharmacokinetics of these radiopharmaceuticals. The major disadvantage of SPECT is its very low detection efficiency $\left(<10^{-4}\right.$ times the emitted number of $\gamma$-rays) because of the use of lead collimators to define the angle of incidence (40). Another imaging modality, PET, offers many advantages over SPECT, and the increasing popularity of clinical PET and PET/CT scanners can facilitate the translation of promising new tracers to clinical applications $(12,41)$.

\section{PET of VEGF/VEGFRs}

A few radiolabeled anti-VEGF antibodies have been reported. VG76e, an IgG1 monoclonal antibody that binds to human VEGF, was labeled with ${ }^{124}$ I for PET of solid tumor xenografts in immunodeficient mice (42). Although VEGF specificity in vivo was demonstrated in that report, the poor immunoreactivity $(<35 \%)$ of the radiolabeled antibody limits the potential use of this tracer. HuMV833, a humanized anti-VEGF monoclonal antibody, has also been labeled with ${ }^{124} \mathrm{I}$ and investigated in a phase I clinical trial (43). Patients with progressive solid tumors were treated with various doses of HuMV833, and PET with ${ }^{124}$ I-HuMV833 was performed to measure the antibody distribution in and clearance from tissues. The antibody distribution and clearance were found to be quite heterogeneous, not only between and within patients but also between and within individual tumors. These results suggested that intrapatient dose escalation approaches or more precisely defined patient cohorts will be needed in the design of future phase I studies with antiangiogenic antibodies such as HuMV833.

In a recent study, bevacizumab was labeled with ${ }^{111}$ In and ${ }^{89} \mathrm{Zr}$ for SPECT and PET, respectively (44). Nude mice xenografted with SKOV-3 human ovarian tumors were injected with ${ }^{89} \mathrm{Zr}$-bevacizumab, ${ }^{111} \mathrm{In}$-bevacizumab, or ${ }^{89} \mathrm{Zr}$-IgG. PET revealed tracer uptake in well-perfused organs up to $24 \mathrm{~h}$ after injection and clear tumor localization at $72 \mathrm{~h}$ after injection and beyond (Fig. 2A). Although the tumor uptake of ${ }^{89} \mathrm{Zr}$-bevacizumab was higher than that of ${ }^{89} \mathrm{Zr}-\mathrm{IgG}$, the absolute tumor uptake $(<8 \% \mathrm{ID} / \mathrm{g})$ was much lower than that of other radiolabeled antibodies reported in the literature (45-47). One flaw of that study (44) was that there was no clear evidence that VEGF expression was upregulated in the tumors. The higher uptake of ${ }^{89} \mathrm{Zr}$-bevacizumab than ${ }^{89} \mathrm{Zr}$-IgG may have been attributable to the different levels of passive targeting of individual antibodies, even though they were isotypematched IgG. Whether the levels of VEGF expression are 


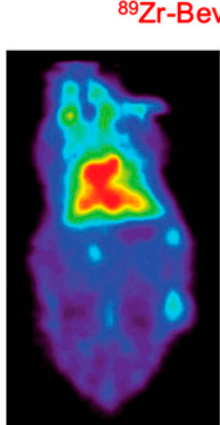

(A) Coronal small-animal PET images of tumor-bearing mouse at 24 and $168 \mathrm{~h}$ after injection of ${ }^{89} \mathrm{Zr}$ bevacizumab. (B) Coronal small-animal PET images of U87MG tumor-bearing mice at 2 and $16 \mathrm{~h}$ after injection of ${ }^{64} \mathrm{Cu}-$ DOTA-VEGF ${ }_{121}$. Small tumor expresses high level of VEGFR-2, and large tumor expresses low level of VEGFR-2. (C) Coronal small-animal PET images of 4T1 tumor-bearing mice at 1 and $19 \mathrm{~h}$ after injection of either ${ }^{64} \mathrm{Cu}$-scVEGF (singlechain VEGF that binds to VEGFR) or equivalent amount of ${ }^{64} \mathrm{Cu}$-inVEGF (inactive VEGF that does not bind to VEGFR). (D) Coronal and sagittal slices containing kidneys (arrowheads) at $4 \mathrm{~h}$ after injection of ${ }^{64} \mathrm{Cu}$-DOTA-VEGF ${ }_{121}$ (binds to both VEGFR-1 and VEGFR-2) or ${ }^{64} \mathrm{Cu}$-DOTAVEGF $_{\text {DEE }}$ (VEGFR-2 specific). Arrows or arrowheads in $\mathrm{A}-\mathrm{C}$ indicate tumors. (Adapted from $(37,44,48,53)$.)

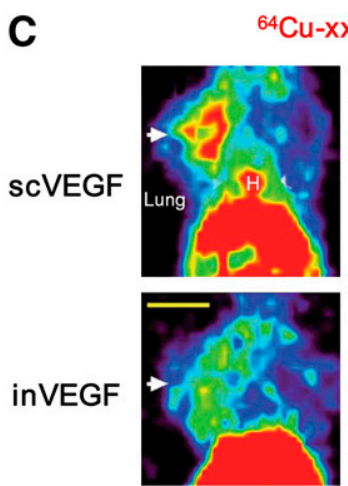

$1 \mathrm{~h}$

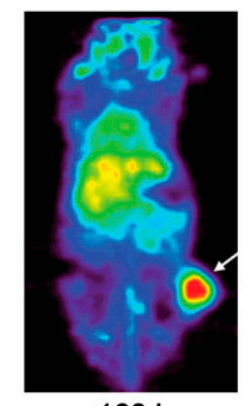

$168 \mathrm{~h}$

B

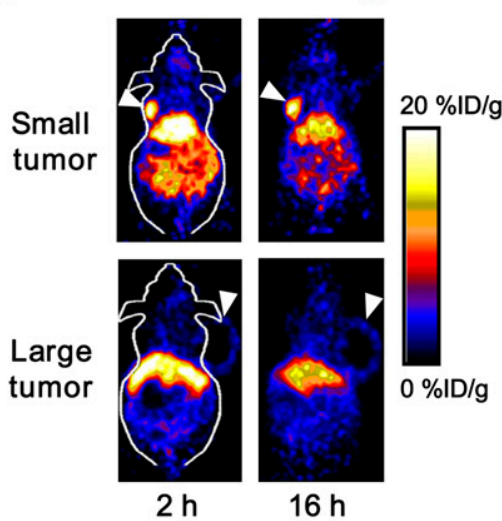

significantly different during different stages of tumor development, in turn leading to different levels of tumor uptake of tracers, needs to be studied.

We recently labeled $\mathrm{VEGF}_{121}$ with ${ }^{64} \mathrm{Cu}$ for PET of VEGFR expression (48). 1,4,7,10-Tetraazacyclododecane$N, N^{\prime}, N^{\prime \prime}, N^{\prime \prime \prime}$-tetraacetic acid (DOTA)-VEGF 121 exhibited nanomolar VEGFR-2-binding affinity (comparable to that of $\mathrm{VEGF}_{121}$ ) in vitro. Small-animal PET imaging revealed rapid, specific, and prominent uptake of ${ }^{64} \mathrm{Cu}$-DOTAVEGF $_{121}(\sim 15 \% \mathrm{ID} / \mathrm{g})$ in highly vascularized small U87MG tumors (high level of VEGFR-2 expression) but significantly lower and sporadic uptake $(\sim 3 \% \mathrm{ID} / \mathrm{g})$ in large U87MG tumors (low level of VEGFR-2 expression) (Fig. 2B). Western blotting of the tumor tissue lysate, immunofluorescence staining, and blocking studies with unlabeled $\mathrm{VEGF}_{121}$ confirmed that the tumor uptake of ${ }^{64} \mathrm{Cu}$-DOTA-VEGF 121 was VEGFR specific. That study demonstrated the dynamic nature of VEGFR expression during tumor progression, in that even in the same tumor model, levels of VEGFR expression were dramatically different at different sizes and stages. These results underscore the importance of imaging of VEGFR expression in anti-VEGFR cancer therapy, because the therapeutically efficacious window may be quite narrow and may also be highly variable among different tumor types. Noninvasive imaging to evaluate the level of VEGFR expression before the initiation of treatment can help with decisions about whether and when to start antiangiogenic treatment. Reli- able and accurate evaluation of the level of VEGFR expression will dramatically improve cancer management.

In a follow-up study, a VEGFR-2-specific fusion protein, $\mathrm{VEGF}_{121} / \mathrm{rGel}\left(\mathrm{VEGF}_{121}\right.$ linked to recombinant plant toxin gelonin) was used to treat orthotopic glioblastoma in a mouse model (49). Before the initiation of treatment, small-animal PET imaging with ${ }^{64} \mathrm{Cu}-\mathrm{VEGF}_{121} / \mathrm{rGel}$ was performed to evaluate the tumor-targeting efficacy and pharmacokinetics of the fusion protein and thereby determine the dose interval. (This type of study with a radiolabeled drug clearly demonstrates the power of molecular imaging, in that cancer patients can also be selected for molecular cancer therapy on the basis of pretreatment screening with a radiolabeled drug [analog].) During and after treatment, the therapeutic efficacy of $\mathrm{VEGF}_{121} / \mathrm{rGel}$ was successfully monitored by multimodality imaging with ${ }^{18} \mathrm{~F}$-fluorothymidine PET, MRI, and bioluminescence imaging, with all results supported by ex vivo histologic findings. That study suggested that clinical multimodality imaging and therapy with $\mathrm{VEGF}_{121} / \mathrm{rGel}$ may provide an effective means of prospectively identifying patients who will benefit from $\mathrm{VEGF}_{121} / \mathrm{rGel}$ therapy and then stratify, personalize, and monitor treatment to obtain optimal survival outcomes.

VEGF $_{121}$ was recently labeled with ${ }^{64} \mathrm{Cu}$ site specifically (37). Compared with the ${ }^{99 \mathrm{~m} T c-l a b e l e d ~ a n a l o g}$, for which tumor uptake $(\sim 3 \% \mathrm{ID} / \mathrm{g})$ was lower than that in most of the normal organs and kidney uptake was about $120 \% \mathrm{ID} / \mathrm{g}$, 
${ }^{64} \mathrm{Cu}$-labeled pegylated $\mathrm{VEGF}_{121}$ showed similar tumor uptake $(\sim 2.5 \% \mathrm{ID} / \mathrm{g})$ and lower kidney uptake, about 65 $\%$ ID/g (Fig. 2C). Whether such site-specific labeling through an extra cysteine tag has advantages over direct labeling at lysine side-chain amino groups, which has been shown not to affect VEGFR-2-binding affinity (48), remains to be determined. Direct comparison of the 2 labeling methods and of other potential strategies is needed to determine which tracer is more suitable for clinical evaluation.

All VEGF-A isoforms bind to both VEGFR-1 and VEGFR-2 (19). In the imaging studies reported to date, specificity for either VEGFR-1 or VEGFR-2 was rarely achieved, because most of the tracers were based on VEGF-A isoforms. Because of a high level of VEGFR-1 expression, rodent kidneys can take up a significant amount of a VEGFA-based tracer, a fact that often makes the kidneys the dose-limiting organs $(37,48,50)$. Because VEGFR-2 is generally accepted to be more functionally important than VEGFR-1 in cancer progression $(19,51)$, the ability to image VEGFR-2 expression by PET can be a valuable tool for evaluating patients with a variety of malignancies, particularly those undergoing anti-VEGFR-2 therapies.

Alanine-scanning mutagenesis has revealed that $\mathrm{Arg}^{82}$, $\mathrm{Lys}^{84}$, and $\mathrm{His}^{86}$, located in a hairpin loop of $\mathrm{VEGF}_{165}$, are critical for VEGFR-2 binding and that some negatively charged residues, $\mathrm{Asp}^{63}$, Glu${ }^{64}$, and $\mathrm{Glu}^{67}$, are associated with VEGFR-1 binding (52). Because $\mathrm{VEGF}_{121}$ is a soluble, nonheparin-binding variant containing the full biologic and receptor-binding activities of the larger variants (19), we recently developed a VEGFR-2-specific PET tracer based on mutated $\mathrm{VEGF}_{121}$ (53). The D63AE64AE67A mutant of $\mathrm{VEGF}_{121}$ (denoted as $\mathrm{VEGF}_{\mathrm{DEE}}$ ) was generated by recombinant DNA technology. Compared with $\mathrm{VEGF}_{121}, \mathrm{VEGF}_{\mathrm{DEE}}$ had an affinity for binding to VEGFR-1 that was 20-fold lower, without a significant reduction in VEGFR-2-binding affinity. Small-animal PET imaging revealed that both ${ }^{64} \mathrm{Cu}$-DOTAVEGF $_{121}$ and ${ }^{64} \mathrm{Cu}-\mathrm{DOTA}-\mathrm{VEGF}_{\mathrm{DEE}}$ had rapid, prominent, and comparable levels of activity accumulation in VEGFR2-expressing tumors. Meanwhile, the renal uptake of ${ }^{64} \mathrm{Cu}-\mathrm{DOTA}-\mathrm{VEGF}_{\mathrm{DEE}}$ was much lower than that of ${ }^{64} \mathrm{Cu}-$ DOTA-VEGF ${ }_{121}$ because rodent kidneys express a high level of VEGFR-1 (Fig. 2D). Significantly lower kidney uptake of ${ }^{64} \mathrm{Cu}-\mathrm{DOTA}-\mathrm{VEGF}_{\mathrm{DEE}}$, conferring much lower renal toxicity than other VEGF-A-based tracers, makes this tracer highly amenable for translation to clinical applications. Further improvement in VEGFR-2-binding affinity and specificity, pharmacokinetics, and tumor-targeting efficacy through the generation of other $\mathrm{VEGF}_{121}$ mutants is currently being investigated.

\section{NON-RADIONUCLIDE-BASED IMAGING OF VEGF/VEGFR EXPRESSION}

Dynamic contrast-enhanced MRI (DCE-MRI), a noninvasive technique that can provide parameters related to tissue perfusion and permeability for examination of the tumor vasculature, has been used to indirectly measure vascular permeability $(54,55)$. Because VEGF is the principal mediator of vascular permeability, researchers have tried to correlate DCE-MRI parameters with levels of VEGF expression. In some reports, the MRI parameters correlated relatively well with VEGF expression, which was determined by immunohistologic staining (56-58). However, in many other reports, such a correlation was not observed (59-61). Direct measurement of VEGF/VEGFR expression with mMRI, with which contrast agent-mediated alterations in tissue relaxation times can allow for the detection and localization of molecular markers of diseases (62), has not been achieved. However, VEGF/VEGFR imaging with targeted ultrasound and optical techniques has been reported in the last few years.

\section{Ultrasound Imaging of VEGFRs}

Ultrasound (ultrasonography) is the most commonly used clinical imaging modality because of its safety, low cost, ease of use, and wide availability (63). The contrast of ultrasound is dependent on the sound speed, sound attenuation, backscatter, and imaging algorithm (64). Ultrasound can be used to image the microcirculation with both Doppler and microbubble methods (65). The power Doppler signal can be quantified to provide an estimate of relative fractional vascular volume, and microbubbles can reveal blood flow down to the microcirculation level by increasing the signal from smaller vessels. Like DCE-MRI results, noninvasive ultrasound imaging results obtained during tumor development or antiangiogenic cancer therapy have been compared with ex vivo histologic findings (66-69). Although good agreement was observed in some cases, these results did not represent noninvasive direct imaging of VEGF/VEGFR expression. It was not until very recently that in vivo ultrasound imaging of VEGF/VEGFR expression was reported (70).

Contrast-enhanced ultrasound (CEU) imaging typically uses microbubbles, which are at least several micrometers in diameter; therefore, only the tumor endothelium can be targeted, because these microbubbles are too large to extravasate (71). In a mouse model of pancreatic adenocarcinoma, targeted microbubbles were used to image and quantify the vascular effects of 2 antitumor therapies on both subcutaneous and orthotopic pancreatic tumors (70). Tumor-bearing mice were treated with anti-VEGF monoclonal antibodies or gemcitabine (a chemotherapy drug), and the localization of antibody-conjugated microbubbles to VEGFR-2-expressing or VEGF-activated blood vessels (the VEGF-VEGFR complex) was monitored by CEU (Fig. $3 \mathrm{~A})$. Significant signal enhancement of the tumor vasculature was observed with the targeted microbubbles relative to untargeted or control IgG-conjugated microbubbles. The video signal intensity from the targeted microbubbles also correlated with the level of expression of the target (either VEGFR-2 or the VEGF-VEGFR complex), as well as with the microvessel density in tumors under therapy. In another report, VEGFR-2 expression in 2 murine tumor models was 
A

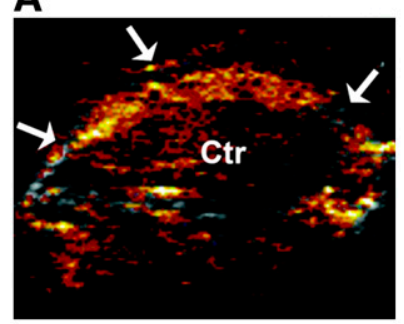

Control

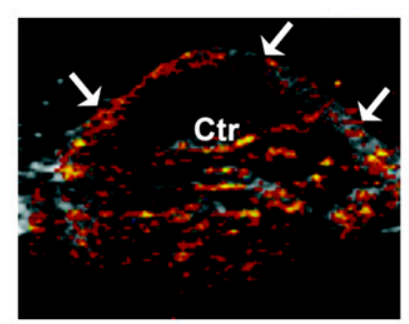

Treatment
B

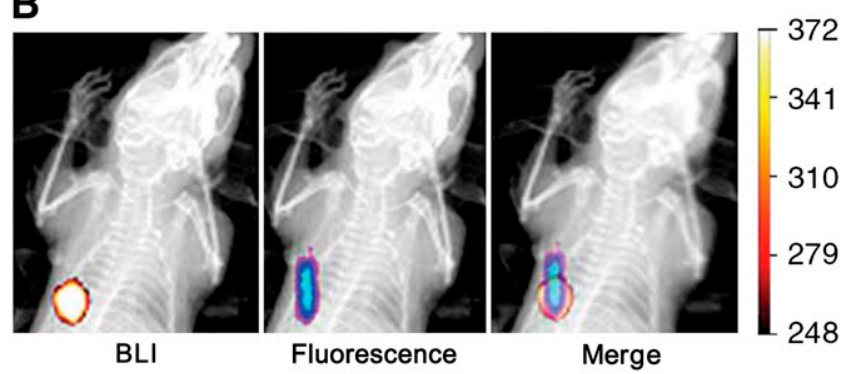

FIGURE 3. Non-radionuclide-based imaging of VEGFR expression. (A) CEU images obtained with VEGFR-2-targeted microbubbles in control and treated animals. Video intensity is significantly lower in mice receiving anti-VEGF treatment. Arrows indicate periphery of tumor; $\mathrm{Ctr}=$ center of tumor. (B) Bioluminescence imaging (BLI; after injection of D-luciferin), fluorescence imaging (after injection of Cy5.5-VEGF), and merged images for 4T1 tumor-bearing mouse. (Adapted from $(37,70)$.)

imaged with microbubbles conjugated to anti-VEGFR-2 monoclonal antibodies (72). The targeted microbubbles produced a significantly higher average video signal intensity than control microbubbles in both tumor models, and the video signal intensity was significantly lower when anti-VEGFR-2 antibodies (blocking antibodies) were used, demonstrating target specificity. These 2 studies demonstrated that targeted microbubbles can be a novel and attractive tool for the noninvasive imaging of tumor angiogenesis, as well as for the in vivo monitoring of vascular effects after therapy.

Ultrasound has a relatively high spatial resolution (50$500 \mu \mathrm{m}$ ), yet it also has some disadvantages, such as relatively poor tissue penetration (usually a few centimeters, depending on the frequency used) and limited sensitivity (11). Further development of molecular imaging with ultrasound will involve the expansion of targeted disease states, improvements in technology for ligand attachment to microbubbles, better characterization of the acoustic behavior of targeted contrast agents, and the development of more sensitive and accurate imaging methods. Acoustic destruction of "payload-bearing" microbubbles has been used to deliver drugs or to augment gene transfection (73). Therefore, angiogenesis-targeted microbubbles may also have future applications in site-specific cancer therapy.

\section{Optical Imaging of VEGFRs}

Optical imaging is a relatively low-cost method suitable primarily for small-animal studies. In fluorescence imaging, excitation light illuminates the subject, and the emission light is collected at a shifted wavelength (11). Fluorescence imaging has many disadvantages: it is not quantitative, the image information is surface weighted because of tissue absorption, and typically a significant background signal is observed because of tissue autofluorescence (74).

Human VEGF was conjugated to a fluorescent dye, Cy5.5 (maximum emission, $696 \mathrm{~nm}$ ), and tested for in vivo imaging $(75,76)$. Although tumor contrast was observed after administration of the probe, no information about the whole-body distribution of Cy5.5-VEGF in these studies was reported. Interestingly, the bioluminescence signal of luciferase-transfected tumor cells does not overlap well with the fluorescence signal of Cy5.5-VEGF in some cases (Fig. 3B) (37). Because it has been reported that some cyanine dyes can accumulate in tumors even without conjugation to a targeting ligand $(77,78)$, extra care needs to be taken in interpreting the experimental findings of fluorescent dye-based imaging. Whenever feasible, blocking experiments should be performed to confirm the receptor specificity of the probe in vivo.

Because of the limited tissue penetration and intense scattering of light, optical imaging will be possible in humans only at limited sites, such as tissues and lesions close to the skin surface and tissues accessible by endoscopy and during intraoperative visualization $(79,80)$. A near-infrared (700-900 nm) fluorescence (NIRF) imaging approach, in which the absorbance spectra for all biomolecules reach minima, thus providing a clear window for in vivo optical imaging (81), will provide better opportunities for visualizing tumor angiogenesis in both small-animal models and clinical settings.

\section{FUTURE DIRECTIONS FOR VEGF/VEGFR IMAGING}

Among all of the modalities used for VEGF/VEGFR imaging, PET is the most widely studied. Peptidic VEGFR antagonists that can be labeled with ${ }^{11} \mathrm{C}$ or ${ }^{18} \mathrm{~F}$ should be investigated. Because $1 \mathrm{~h}$ after injection is usually sufficient for peptide-based tracers to clear from the nontargeted organs and produce high-contrast PET images $(82,83)$, whereas it can take several hours or even days before highcontrast PET images can be obtained with antibody-based tracers (45-47), small-molecule-based or peptide-based tracers can allow for higher throughput. Multimodality imaging of VEGF/VEGFR expression, in which the same probe can be simultaneously detected by 2 or more imaging modalities, needs to be developed. When the advantages of various imaging modalities are combined, quantitative and more accurate information that no single modality alone can offer can be obtained. Dual-modality probes that combine radionuclide-based imaging (very sensitive and highly quantitative) and non-radionuclide-based approaches (such as optical imaging, which can significantly facilitate ex vivo validation of data obtained in vivo, and 
MRI probes, which can provide high-resolution anatomic information) are of particular interest.

Imaging of the expression of both VEGF and VEGFRs is important for cancer diagnosis and monitoring of therapeutic efficacy against cancer. Because of the soluble and dynamic nature of VEGF proteins, imaging of VEGF expression is much more challenging than imaging of VEGFR expression and has not been very well studied. Examining tumors in the same animals or cancer patients with both VEGF- and VEGFR-targeted tracers may provide important insights about the kinetics of expression of both VEGF and VEGFRs during cancer development and cancer therapy.

Dual-isotope SPECT of VEGF/VEGFR expression with tracers labeled with various radioisotopes can be investigated. It is possible that even more radioisotopes with different energies can be detected simultaneously, making use of the major advantage of SPECT over PET. Multiplex optical imaging of such protein pairs can also be studied; quantum dots (QDs) can play an important role in such studies because of their broad excitation and narrow emission spectra, which make them ideal for multiplexing studies $(80,84)$. Fluorescence resonance energy transfer may be explored for imaging VEGF-VEGFR interactions. Although fluorescence resonance energy transfer has been well studied in cell-based assays $(85,86)$, whether it can be achieved successfully in vivo for studying protein-protein interactions remains to be demonstrated. A split reporter gene strategy, in which the reporter protein produces a signal only when the 2 proteins of interest interact and are in close proximity to each other (87), may enable long-term and accurate measurements of VEGF-VEGFR interactions in vivo. Nanotechnology may also have many applications in the imaging of VEGFR expression in the future. Although to date no literature reports are available for VEGFRtargeted nanoparticles, many groups have investigated the use of nanoparticles for the targeting of another vasculaturerelated protein, integrin $\alpha_{\mathrm{v}} \beta_{3}$.

\section{INTEGRIN $\alpha_{\mathbf{v}} \boldsymbol{\beta}_{3}$}

Integrins are a family of cell adhesion molecules consisting of 2 noncovalently bound transmembrane subunits ( $\alpha$ and $\beta$ ), both type I membrane proteins with large extracellular segments that pair to create heterodimers with distinct adhesive capabilities (88). In mammals, 18 $\alpha$-subunits and $8 \beta$-subunits have been characterized; these subunits assemble into at least 24 different receptors (Fig. 4). Integrin signaling plays a key role in tumor angiogenesis and metastasis (89). Integrins expressed on endothelial cells modulate cell migration and survival during tumor angiogenesis, whereas integrins expressed on carcinoma cells potentiate metastasis by facilitating invasion and movement across blood vessels. Integrin $\alpha_{v} \beta_{3}$, which binds to arginine-glycine-aspartic acid (RGD)-containing components of the extracellular matrix, is significantly upregulated on tumor vasculature but not on quiescent endothelium $(89,90)$.

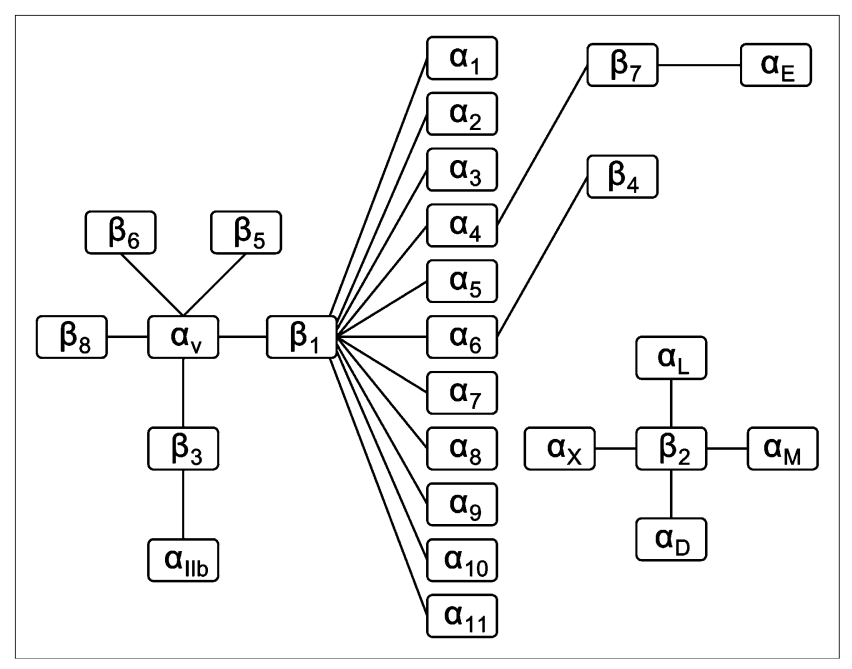

FIGURE 4. Integrin family, composed of 24 heterodimers.

Among all of the integrins discovered to date, integrin $\alpha_{v} \beta_{3}$ is the most extensively studied. Many monoclonal antibodies, cyclic RGD peptide antagonists, and peptidomimetic agents against integrin $\alpha_{v} \beta_{3}$ have been used for antiangiogenic cancer therapy (5).

Most studies of the imaging of integrin $\alpha_{v} \beta_{3}$ have used RGD peptides as the targeting ligands, and many excellent reviews are available (15,91-93). In the majority of cases, RGD peptide-based tracers bind to integrin $\alpha_{v} \beta_{3}$ expressed on both the tumor vasculature and tumor cells. In a strict sense, these cases are not truly representative of tumor angiogenesis imaging because the probes target mainly integrin $\alpha_{v} \beta_{3}$-positive tumor cells. Several nanoparticlebased probes have been used for integrin $\alpha_{\mathrm{v}} \beta_{3}$ imaging (Fig. 5). Because of their large overall size (from $20 \mathrm{~nm}$ to a few micrometers in diameter), these probes either do not extravasate at all or do not extravasate well. Therefore, they almost exclusively target integrin $\alpha_{v} \beta_{3}$ on the tumor vasculature and indeed image tumor angiogenesis. Compared with the vast number of literature reports on integrin $\alpha_{v} \beta_{3}$ imaging with peptide- or protein-based tracers (94-110), nanoparticle-based imaging of integrin $\alpha_{v} \beta_{3}$ is relatively rare. Here we summarize the state of the art for the imaging of tumor vasculature integrin $\alpha_{v} \beta_{3}$ with nanoparticles.

\section{RADIONUCLIDE-BASED IMAGING OF INTEGRIN $\alpha_{\mathrm{v}} \boldsymbol{\beta}_{3}$ EXPRESSION}

The use of molecularly targeted nanoparticles affords many advantages over conventional approaches. First, hundreds, thousands, or even more imaging labels or combinations of labels for various imaging modalities can be attached to a single nanoparticle and thereby can lead to a dramatic increase in signal intensity. Second, multiple, potentially different, targeting ligands on the same nanoparticle can provide selectivity enhancement. Third, the ability to integrate means to bypass biologic barriers for the nanoparticle can enhance targeting efficacy. With con- 


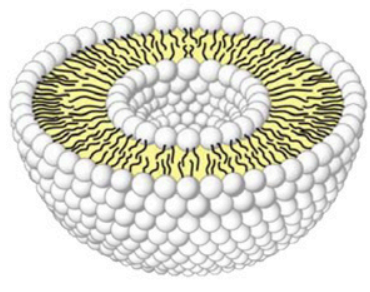

Liposome

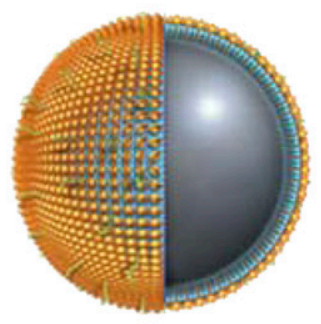

Perfluorocarbon

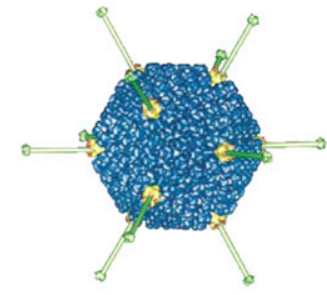

Adenovirus

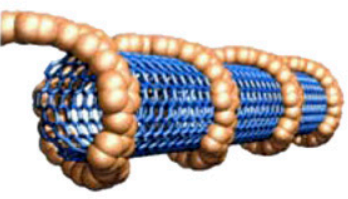

Nanotube

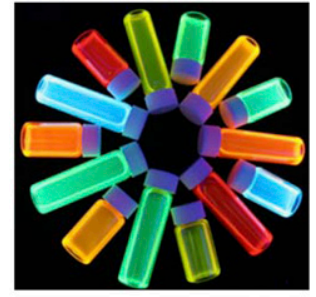

Quantum Dot

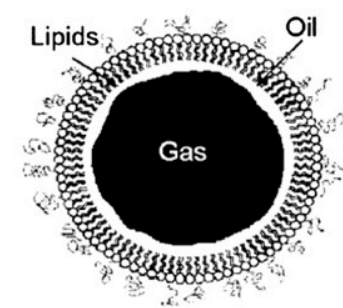

Microbubble tinuous multidisciplinary efforts, nanoparticle-based approaches will shed new light on molecular diagnostics and molecular therapy targeting tumor angiogenesis.

To date, there has been only one report on SPECT of integrin $\alpha_{v} \beta_{3}$ with a nanoparticle-based tracer. ${ }^{111}$ In-Labeled perfluorocarbon nanoparticles were tested for the detection of tumor angiogenesis in New Zealand White rabbits implanted with Vx-2 lung carcinoma tumors (111). Nanoparticles bearing approximately $10^{111}$ In atoms per particle were found to provide better tumor-to-muscle ratios than nanoparticles bearing approximately $1{ }^{111}$ In atom per particle. At $18 \mathrm{~h}$ after injection, the mean tumor activity in rabbits receiving integrin $\alpha_{\mathrm{v}} \beta_{3}$-targeted nanoparticles was about 4-fold higher than that obtained with control nanoparticles.

Recombinant adenovirus (Ad; about $70 \mathrm{~nm}$ in diameter) has been widely used as a vehicle for delivering genes to mammalian cells because of its unparalleled gene transfer efficacy in vivo (112). However, the broad native tropism of Ad is a major concern, and specific targeting can enhance gene therapy efficacy with lower toxicity (113-115). We successfully redirected the Ad tropism by chemical modification of the fiber knobs with pegylated RGD peptides (116). The in vivo infectivity of Ad vectors expressing the herpes simplex virus type 1 mutant thymidine kinase gene after intravenous administration into integrin $\alpha_{v} \beta_{3}$-positive tumor-bearing mice was measured by small-animal PET imaging with 9-[4- ${ }^{18} \mathrm{~F}$-fluoro-3-(hydroxymethyl)butyl]guanine as the PET reporter probe $(117,118)$. Pegylation completely abrogated the coxsackievirus and adenovirus receptor-knob interaction and the infectivity. RGD modification partially restored the viral infectivity to integrin $\alpha_{\mathrm{v}} \beta_{3}$-positive tumors. This strategy provided a robust platform for site-specific gene delivery and noninvasive monitoring of transgene delivery efficacy and homing, which may have clinical applications. In another study, bioluminescence imaging was used to noninvasively mon- itor the redirected tropism of this chemically modified Ad, which carries a firefly luciferase reporter gene (119).

Single-wall carbon nanotubes (SWNTs) exhibit unique size, shape, and physical properties that make them promising candidates for biologic applications $(120,121)$. We recently investigated the biodistribution of ${ }^{64} \mathrm{Cu}$-labeled SWNTs in mice by PET and ex vivo Raman spectroscopy (122). Properly pegylated SWNTs were found to have a relatively long circulation half-life (a few hours) and low uptake by the reticuloendothelial system (RES). Efficient targeting of integrin $\alpha_{\mathrm{v}} \beta_{3}$-positive U87MG tumors in mice ( $\sim 15 \% \mathrm{ID} / \mathrm{g}$ ) — among the highest ever reported for any nanoparticles-was also achieved with RGD peptideconjugated SWNTs (Fig. 6). The unique Raman signatures of SWNTs enabled direct measurement of SWNTs in various mouse tissues and confirmation of the radionuclidebased results (Fig. 6). Virtually no kidney uptake was observed on the basis of Raman measurement of the tissue homogenate, although a small fraction of ${ }^{64} \mathrm{Cu}$ detached from the SWNTs did show appreciable kidney uptake on PET. Further investigation of SWNTs, which have large surface areas that may be functionalized in a variety of ways for the attachment of therapeutic agents and other moieties (120), as a nanoplatform for integrated multimodality imaging and molecular therapy is under way.

Radiolabeled nanoparticles represent a new class of probes with enormous potential for clinical applications. The radiolabel can enable quantitative measurements of tumor-targeting efficacy and pharmacokinetics, provided that the radiolabel on the nanoparticle is stable under physiologic conditions. However, dissociation of the radionuclide (typically metal) from the chelator or the radionuclide-containing polymer coating from the nanoparticle can cause significant differences between the nanoparticle distribution and the radionuclide distribution. The biodistribution of SWNTs in animals has been studied with other 


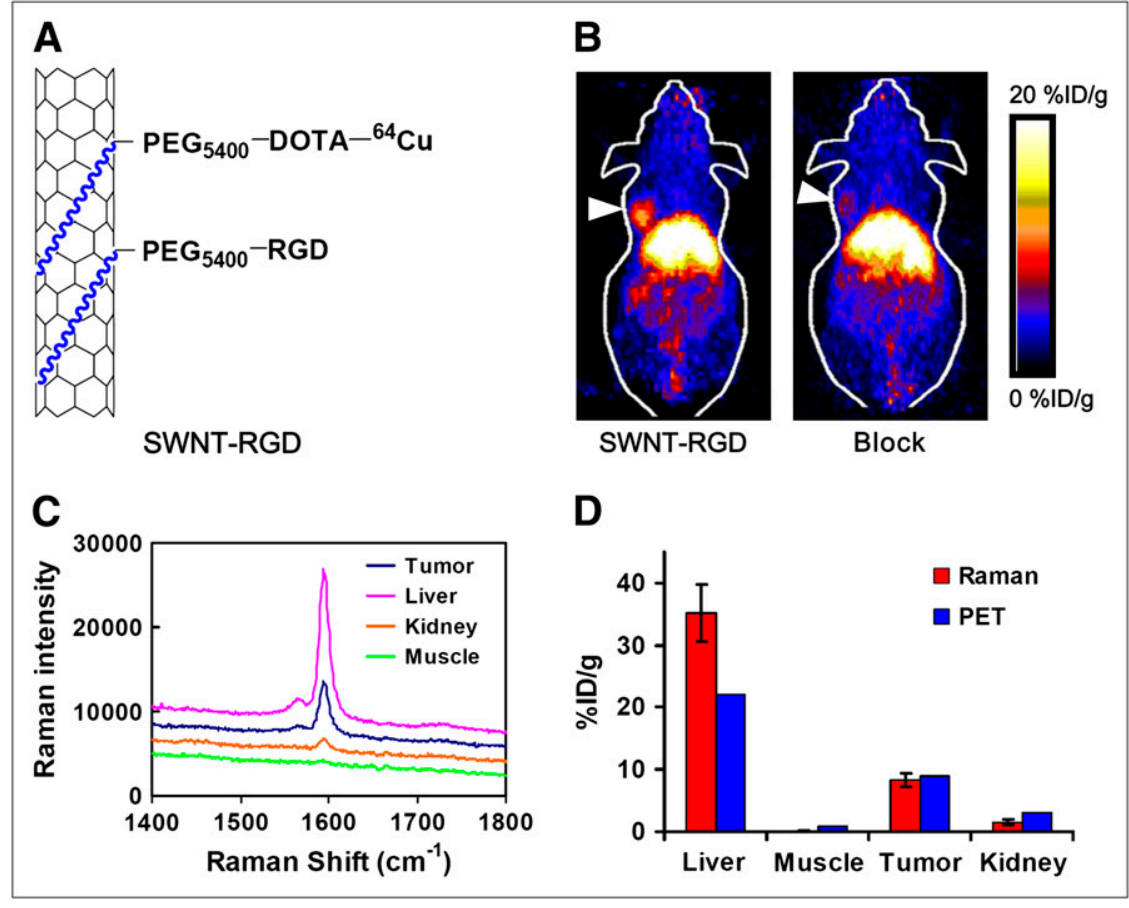

FIGURE 6. SWNTs for tumor integrin $\alpha_{\mathrm{v}} \beta_{3}$ targeting. (A) Schematic drawing of functionalized SWNTs. Phospholipid (blue segments) bind strongly to side walls of SWNTs. Polyethylene glycol (PEG) chains provide water solubility, and DOTA molecules are used to chelate ${ }^{64} \mathrm{Cu}$ for PET. (B) Two-dimensional projection of small-animal PET images of U87MG tumor-bearing mice at $8 \mathrm{~h}$ after injection of RGD-conjugated SWNTs with (Block) or without coinjection of RGD peptides. Arrowheads indicate tumors. (C) Raman spectra of tissue homogenate, providing direct evidence of presence of SWNTs in tumor. (D) Good agreement of biodistribution data obtained by PET and ex vivo Raman measurements, confirming in vivo stability and tumor-targeting efficacy of RGD-conjugated SWNTs. (Adapted from (122).) radiolabels besides ${ }^{64} \mathrm{Cu}(123,124)$. Surprisingly, these SWNTS were reported to undergo either complete or partial renal clearance in mice, with little uptake by the liver or other organs of the RES. These findings defy the general trend of high RES uptake for nanoparticles and deserve further investigation and validation. Direct measurement of SWNTs in various tissues on the basis of intrinsic Raman signals, as well as rigorous validation of the stability of the radiolabel on the nanoparticle, should always be performed to obtain more reliable results (122). Studies have shown that typically only molecules with masses of less than $70 \mathrm{kDa}$ (a few nanometers in diameter) undergo renal clearance $(125,126)$. The SWNTs used in the reports mentioned so far are typically more than $200 \mathrm{~nm}$ long, even up to a few micrometers (122-124). It is very unlikely that they can be cleared from the kidneys unless severe kidney damage has occurred.

\section{NON-RADIONUCLIDE-BASED IMAGING OF INTEGRIN $\alpha_{v} \beta_{3}$ EXPRESSION}

A variety of nanoparticles have been used for nonradionuclide-based imaging of integrin $\alpha_{v} \beta_{3}$ during tumor angiogenesis. For mMRI, $\mathrm{Gd}^{3+}$-containing nanoparticles (liposomes and perfluorocarbon) and ultrasmall superparamagnetic iron oxide (SPIO) particles have been investigated. Targeted ultrasound has been limited exclusively to microbubbles, and optical imaging of vascular integrin $\alpha_{v} \beta_{3}$ has been achieved only with RGD peptide-conjugated QDs.

\section{mMRI of Integrin $\alpha_{\mathrm{v}} \boldsymbol{\beta}_{3}$}

MRI detects the interactions of protons (or certain other nuclei) with each other and with the surrounding molecules in a tissue of interest (127). Different tissues have different relaxation times, which can result in endogenous MR contrast. Exogenous contrast agents can further enhance this contrast by selectively shortening either the T1 (longitudinal) or the T2 (transverse) relaxation time $(128,129)$. The MR image can be weighted to detect differences in either $\mathrm{T} 1$ or $\mathrm{T} 2$ by adjusting parameters during data acquisition. Traditionally, $\mathrm{Gd}^{3+}$ chelates have been used to enhance T1 contrast (130), and iron oxide nanoparticles have been used to increase T2 contrast (131).

$\mathrm{Gd}^{3+}$-containing paramagnetic liposomes $(300-350 \mathrm{~nm}$ in diameter) have been used for mMRI of integrin $\alpha_{\mathrm{v}} \beta_{3}$ expression (132). In that study, mMRI of squamous cell carcinomas in a rabbit model was achieved with LM609, a mouse antihuman integrin $\alpha_{\mathrm{v}} \beta_{3}$ monoclonal antibody, as the targeting ligand (Fig. 7A). Peptidomimetic integrin $\alpha_{\mathrm{v}} \beta_{3}$ antagonist-conjugated magnetic nanoparticles were tested in a Vx-2 squamous cell carcinoma model with the common clinical field strength of $1.5 \mathrm{~T}$ (133). The targeted nanoparticles increased the MR signal dramatically in the periphery of the tumor at $2 \mathrm{~h}$ after injection. Despite their relatively large size $(\sim 270 \mathrm{~nm}$ in diameter), these nanoparticles penetrated into the leaky tumor neovasculature but did not migrate into the interstitium in appreciable amounts. In a later report, athymic nude mice bearing human melanoma tumors were successfully imaged with systemically injected integrin $\alpha_{v} \beta_{3}$-targeted paramagnetic nanoparticles (134). Very small regions (about $30 \mathrm{~mm}^{3}$ ) of angiogenesis associated with nascent melanoma tumors were visualized by this technique, which may enable phenotyping and staging of early melanomas in clinical settings. 
A
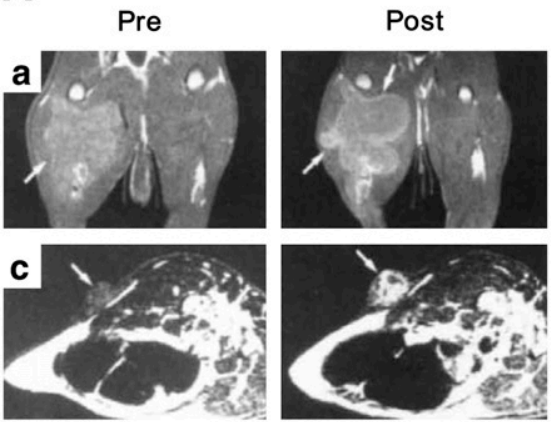

Targeted

B

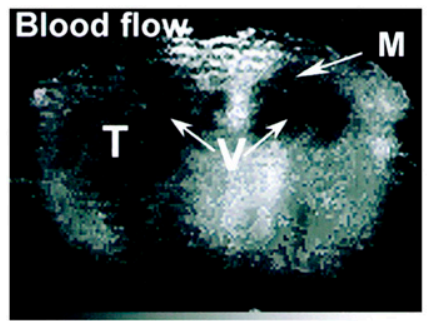

7. Non-radionuclide-base imaging of integrin $\alpha_{v} \beta_{3}$ during tumor angiogenesis. (A) T1-weighted images of rabbits before (Pre) and after (Post) injection of targeted liposomes (a and c) and control liposomes (b and d). Arrows indicate tumors. (B) CEU images of rat with brain tumor, depicting parametric perfusion data (top) and signal enhancement from integrin $\alpha_{v} \beta_{3}$-targeted microbubbles (bottom). $\mathrm{M}=$ periventricular metastasis; $\mathrm{T}=$ tumor; $\mathrm{V}=$ ventricles. (C) In vivo NIRF imaging of U87MG tumor-bearing mice injected with 200 pmol of QD705-RGD or QD705. Mouse autofluorescence is color coded green, and unmixed QD signal is color coded red. Arrows indicate tumors. (Adapted from $(132,139,143)$.)

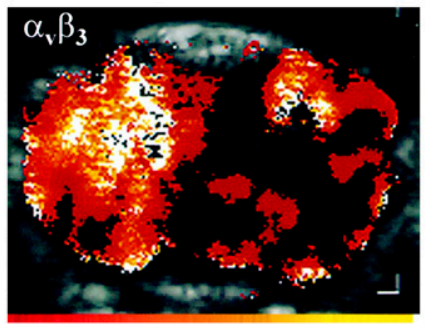

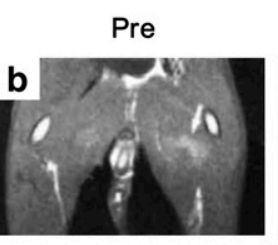
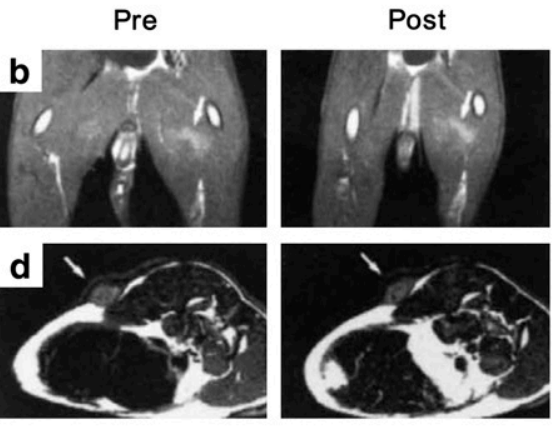

Control

C

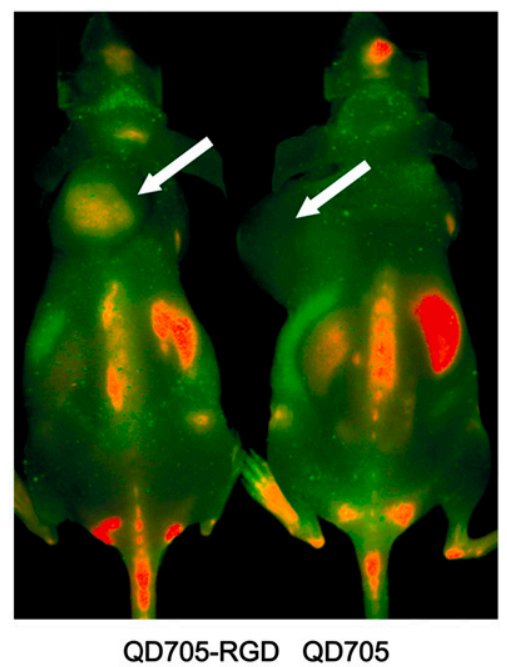

All of the studies mentioned so far used $\mathrm{Gd}^{3+}$ for enhancing $\mathrm{T} 1$ contrast, which can be reliably detected only at millimolar concentrations. SPIO nanoparticles can be detected at much lower concentrations because of their high magnetism (131). Recently, integrin $\alpha_{\mathrm{v}} \beta_{3}$-targeted ultrasmall SPIO nanoparticles were used with a 1.5-T MRI scanner for the noninvasive differentiation of tumors with large and small fractions of integrin $\alpha_{\mathrm{v}} \beta_{3}$-positive tumor vessels (135). After injection of RGD peptide-conjugated ultrasmall SPIO nanoparticles, T2*-weighted MR images revealed the heterogeneous distribution of integrin $\alpha_{\mathrm{v}} \beta_{3}$-positive tumor vessels, as evidenced by an irregular signal intensity decrease. In contrast, the signal intensity decreased more homogeneously in the control tumor, with predominantly small and uniformly distributed vessels.

The major disadvantage of MRI is its inherent low sensitivity, which can be partially compensated for only by using higher magnetic fields (4.7-14 T), acquiring data for much longer periods, and using exogenous contrast agents. Although proof-of-principle studies have been reported for mMRI of integrin $\alpha_{v} \beta_{3}$ and many other targets (62), whether mMRI can significantly improve cancer management remains unclear. Some other techniques, such as hyperpolarized MRI (136) and chemical exchange saturation transfer/ paramagnetic chemical exchange saturation transfer (137), may play important roles in shaping the future of mMRI.

\section{Ultrasound Imaging of Integrin $\boldsymbol{\alpha}_{\mathrm{v}} \boldsymbol{\beta}_{3}$}

Specific targeting of microbubbles can be accomplished by ligand conjugation to the microbubble surface with various strategies $(63,138)$. Targeted ultrasound imaging of integrin $\alpha_{\mathrm{v}} \beta_{3}$ during tumor angiogenesis has been reported (139). Athymic nude rats were inoculated intracerebrally with U87MG human glioblastoma cells. At 2 or 4 wk after implantation, CEU was performed with microbubbles (3-4 $\mu \mathrm{m}$ in diameter) coated with echistatin, an RGD-containing disintegrin, which binds specifically to integrin $\alpha_{v} \beta_{3}(140)$. CEU perfusion imaging with nontargeted microbubbles was also performed to determine the tumor microvascular blood volume and blood velocity (Fig. 7B). The CEU signal was found to be highest at the periphery of tumors, where integrin expression was most prominent as indicated by immunohistochemistry, and correlated well with the tumor microvascular blood volume. In a later study, the detection of tumor neovasculature in athymic nude mice was also achieved with a research ultrasound scanner after the injection of integrin $\alpha_{v} \beta_{3}$-targeted perfluorocarbon nanoparticles (141). 


\section{Optical Imaging of Integrin $\alpha_{v} \beta_{3}$}

QDs are inorganic fluorescent semiconductor nanoparticles with many desirable optical properties for imaging applications, such as high quantum yields, high molar extinction coefficients, strong resistance to photobleaching and chemical degradation, continuous absorption spectra spanning the range from UV to near-infrared, narrow emission spectra (typically $20-30 \mathrm{~nm}$ full width at half maximum), and large effective Stokes shifts $(80,84,142)$. Specific targeting can be achieved by attaching targeting ligands to the QD surface. However, in vivo targeting and imaging are very challenging because of the relatively large overall size (typically $>20 \mathrm{~nm}$ in hydrodynamic diameter) and short circulation half-life of QD conjugates.

We reported the NIRF imaging of integrin $\alpha_{v} \beta_{3}$ on tumor vasculature with RGD peptide-conjugated QDs (143). RGD peptides were conjugated to QD705 (emission maximum at $705 \mathrm{~nm}$ ). The QD705-RGD conjugates exhibited high-affinity integrin $\alpha_{v} \beta_{3}$-specific binding in cell cultures and ex vivo. Because a significant background signal is usually observed for in vivo NIRF imaging as a result of tissue autofluorescence, spectral imaging techniques, in which the fluorescence signals of various fluorophores can be separated on the basis of their emission spectra $(144,145)$, were used to better interpret the NIRF imaging results. Tumor contrast was observed as early as $20 \mathrm{~min}$ after QD705-RGD conjugate injection, and the fluorescence intensity in subcutaneous U87MG tumors reached a maximum at $6 \mathrm{~h}$ after injection (Fig. 7C). As with most nanoparticles, the large size of the QD705-RGD conjugates $(\sim 20 \mathrm{~nm}$ in diameter) prevented efficient extravasation; therefore, the QD705-RGD conjugates mainly targeted integrin $\alpha_{v} \beta_{3}$ on the tumor vasculature instead of the tumor cells, as confirmed by ex vivo immunofluorescence staining. Because the sprouting neovasculature in many tumor types overexpresses integrin $\alpha_{v} \beta_{3}$, this probe may have great potential as a universal NIRF probe for tumor angiogenesis imaging.

QD-based imaging may play an important role in imageguided surgery (146). The major obstacles for the translation of QDs to clinical applications are inefficient delivery, potential toxicity, and lack of quantification (80). However, with the development of smaller $(147,148)$, less toxic $(149,150)$, and multifunctional $(151,152)$ QDs and with further improvement of the conjugation strategy, QD-based probes may achieve optimal tumor-targeting efficacy with an acceptable toxicity profile for translation to clinical applications in the near future.

\section{MULTIMODALITY IMAGING OF INTEGRIN $\alpha_{\mathrm{V}} \boldsymbol{\beta}_{3}$ EXPRESSION}

Among all of the molecular imaging modalities, no single modality is perfect and sufficient to obtain all of the necessary information (11). For example, it is difficult to accurately quantify a fluorescence signal in living sub- jects with fluorescence imaging alone, particularly in deep tissues; MRI has high resolution and good soft-tissue contrast but very low sensitivity; and radionuclide-based imaging techniques are very sensitive but have relatively poor spatial resolution. A combination of multiple molecular imaging modalities can offer synergistic advantages over any modality alone. Multimodality imaging with a small-molecule-based probe is very challenging, sometimes impossible, because of the limited number of conjugation sites and potential interference with receptor-binding affinity. On the other hand, nanoparticles have large surface areas to which multiple functional moieties can be attached for multimodality molecular imaging.

A nanoparticle-based probe has been used for both MRI and optical imaging of integrin $\alpha_{\mathrm{v}} \beta_{3}$. MRI-detectable and fluorescent liposomes carrying RGD peptides were evaluated for in vivo tumor imaging (153). Both RGDconjugated liposomes and RAD (a control peptide that does not bind to integrin $\alpha_{\mathrm{v}} \beta_{3}$ )-conjugated liposomes provided enhanced T1-weighted MR contrast. Ex vivo fluorescence microscopy revealed that RGD-conjugated liposomes were specifically associated with the activated tumor endothelium, whereas RAD-conjugated liposomes were located in the extravascular compartment.

We recently developed a QD-based probe for both NIRF imaging and PET of integrin $\alpha_{\mathrm{v}} \beta_{3}$ (154). QD surface modification with RGD peptides allowed for integrin $\alpha_{\mathrm{v}} \beta_{3}$ targeting, and DOTA conjugation enabled PET after ${ }^{64} \mathrm{Cu}$ labeling (Fig. 8). With this dual-modality probe, we quantitatively evaluated tumor-targeting efficacy, an evaluation that was not possible with NIRF imaging alone (143). As in the previous study (143), it was also found that the majority of the probe in the tumor was within the vasculature, as evidenced by excellent overlay of the QD fluorescence signal and vasculature integrin $\alpha_{v} \beta_{3}$ staining. This dual-modality (PET/NIRF imaging) probe can confer sufficient tumor contrast at a concentration much lower than that required for in vivo NIRF imaging (143), significantly reducing the potential toxicity of cadmium-based QDs $(155,156)$, and may hasten the future translation of QD-based imaging agents to clinical and biomedical applications.

These 2 studies demonstrated the feasibility of dualmodality imaging in vivo, but the 2 modalities were not equally effective. The less sensitive modality was used for ex vivo validation of the in vivo results obtained with the more sensitive imaging modality. Although only singlemodality noninvasive imaging was achieved with the dualmodality probe-an achievement that does not take full advantage of the nanoparticle-based approach - the capability of detecting the probe with another imaging modality did provide a convenient method for ex vivo probe detection after harvesting of the targeted tissue, greatly facilitating the validation of the dual-modality probe. It is likely that in the near future, true noninvasive multimodality tumor angiogenesis imaging will be accomplished. 
A

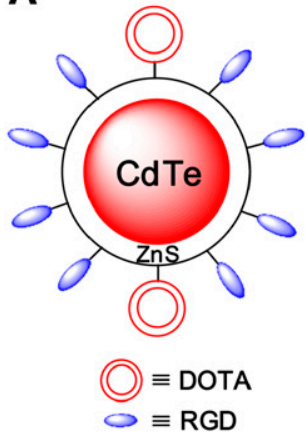

B
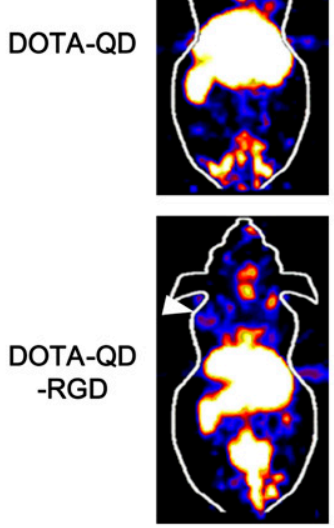

$1 \mathrm{~h}$
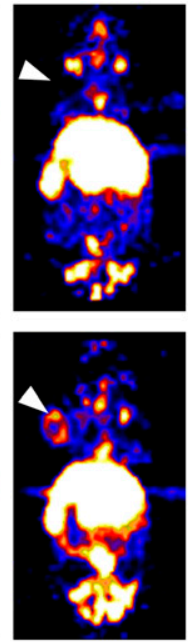

$5 \mathrm{~h}$

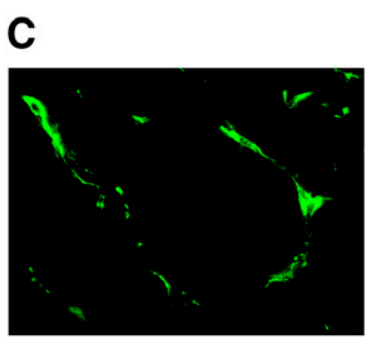

CD31

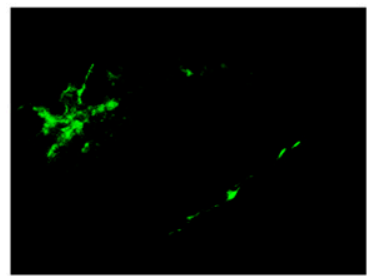

Mouse $\beta_{3}$

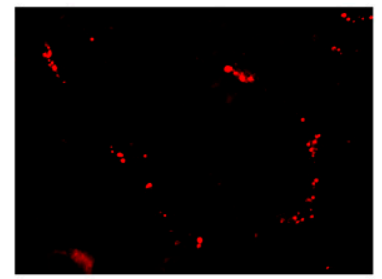

QD

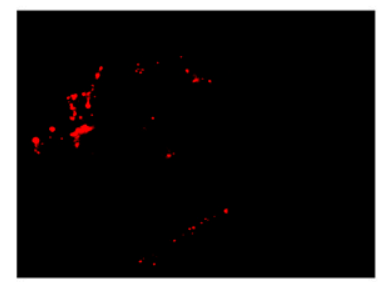

QD

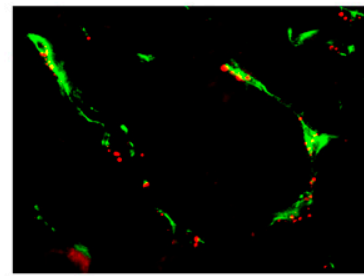

Merge

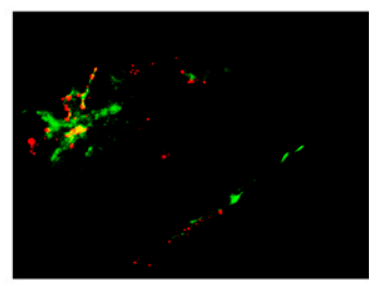

Merge (Adapted from (154).)

\section{SUMMARY AND FUTURE PERSPECTIVES}

A wide variety of targeting molecules (peptides, proteins, and antibodies) have been labeled with various imaging labels (such as radioisotopes, SPIO nanoparticles, fluorescent dyes, QDs, and microbubbles) for PET, SPECT, MRI, optical imaging, and ultrasound imaging of tumor angiogenesis. Noninvasive imaging of tumor angiogenesis has many clinical applications: lesion detection, patient stratification, new drug development and validation, treatment monitoring, and dose optimization. With the development of new tracers with better targeting efficacy and desirable pharmacokinetics, translation to clinical applications will be critical for the maximum benefit of these imaging probes. However, this process has been quite slow so far. Continued development and wider availability of scanners that are dedicated to smallanimal imaging studies, that can provide similar in vivo imaging capabilities in mice, rats, monkeys, and humans $(157,158)$, and that can enable smooth transfer of knowledge and molecular measurements between species will facilitate translation to clinical applications. The U.S. Food and Drug Administration recently developed an exploratory investigational new drug mechanism to allow faster "firstin-human" studies. Therefore, it is expected that in the foreseeable future, tumor angiogenesis imaging will be routinely applied in clinical trials of anticancer agents, leading to personalized molecular therapy.

VEGF, VEGFRs, and integrin $\alpha_{\mathrm{v}} \beta_{3}$ are the key regulators of tumor angiogenesis. Cross-talk between VEGF and integrin $\alpha_{v} \beta_{3}$ recently emerged as a critical factor in the regulation of tumor angiogenesis when it was found that integrin $\alpha_{\mathrm{v}} \beta_{3}$ can regulate the production of VEGF in certain tumor cells (159). Imaging of both VEGF and integrin $\alpha_{\mathrm{v}} \beta_{3}$ can play an important role in understanding the fundamental mechanisms of tumor angiogenesis and antiangiogenic cancer therapy. Many strategies suitable for the imaging of VEGF-VEGFR interactions, in particular, multimodality and nanoparticle-based approaches, can also be applied. Other proteins involved in tumor angiogenesis, 
such as endoglin (CD105) (160), should also be investigated to enlarge the arsenal of angiogenesis imaging probes.

Quantitative imaging of tumor angiogenesis is highly desirable. Although it is generally assumed that noninvasive imaging results correlate with target expression levels, such an assumption has not been extensively validated. In most reports, 2 tumor models are studied; one acts as a positive control, and the other acts as a negative control. Quantitative correlation between target expression levels in vivo and noninvasive imaging data is rare $(45,46,96,103)$. Such correlation is critical for future treatment monitoring applications, because it would be ideal to be able to monitor changes in target expression levels quantitatively, rather than qualitatively, in individual patients.

The most desirable property of nanoparticles is multifunctionality, with which multiple targeting ligands, imaging labels, and therapeutic drugs can be attached to a single nanoparticle and thereby provide enormous sensitivity, throughput, and flexibility (161). One major component of molecular medicine is nanomedicine, in which the ultimate goal is for multifunctional nanoparticles containing both therapeutic components and multimodality imaging labels to allow for efficient, specific in vivo delivery of drugs and accurate, quantitative assessment of the therapeutic efficacy noninvasively over time. Most of the integrin $\alpha_{\mathrm{v}} \beta_{3}$-targeted nanoparticles described to date are far from optimal for clinical applications. In future research on nanoparticle-based tumor angiogenesis imaging, many factors need to be optimized in parallel; these include biocompatibility, in vivo kinetics, targeting efficacy, acute or chronic toxicity, ability to escape from the RES, and cost-effectiveness.

\section{CONCLUSION}

Tumor angiogenesis imaging will play a key role in shaping 21st-century cancer management. To foster the continued discovery and development of tumor angiogenesis imaging probes, cooperative efforts are needed from cellular and molecular biologists in identifying and validating novel imaging targets, from chemists and radiochemists in synthesizing and characterizing imaging probes, and from engineers, medical physicists, and mathematicians in developing high-sensitivity, high-resolution imaging devices and hybrid instruments and better image reconstruction algorithms. Close partnerships among academic researchers, clinicians, pharmaceutical industries, the National Cancer Institute, and the U.S. Food and Drug Administration are also needed to quickly apply tumor angiogenesis imaging to multiple facets of cancer management. The probes developed for tumor angiogenesis imaging can also have broad applications for other angiogenesis-related diseases, such as myocardial infarction, stroke, atherosclerosis, peripheral-artery disease, chronic inflammation, and many others.

\section{ACKNOWLEDGMENTS}

Research carried out in the authors' laboratory was supported, in part, by the National Cancer Institute (R01 120188, R01 CA119053, R21 CA121842, R21 CA102123, P50 CA114747, U54 CA119367, and R24 CA93862), the Department of Defense (W81XWH-07-1-0374, W81XWH04-1-0697, W81XWH-06-1-0665, W81XWH-06-1-0042, and DAMD17-03-1-0143), and a Benedict Cassen Postdoctoral Fellowship from the Education and Research Foundation of the Society of Nuclear Medicine.

\section{REFERENCES}

1. Folkman J. Angiogenesis in cancer, vascular, rheumatoid and other disease. Nat Med. 1995;1:27-31.

2. Bergers G, Benjamin LE. Tumorigenesis and the angiogenic switch. Nat Rev Cancer. 2003;3:401-410.

3. Ferrara N. VEGF and the quest for tumour angiogenesis factors. Nat Rev Cancer. 2002;2:795-803.

4. Nyberg P, Xie L, Kalluri R. Endogenous inhibitors of angiogenesis. Cancer Res. 2005;65:3967-3979.

5. Cai W, Chen X. Anti-angiogenic cancer therapy based on integrin $\alpha_{\mathrm{v}} \beta_{3}$ antagonism. Anticancer Agents Med Chem. 2006;6:407-428.

6. Kerbel R, Folkman J. Clinical translation of angiogenesis inhibitors. Nat Rev Cancer. 2002;2:727-739.

7. Folkman J. Angiogenesis: an organizing principle for drug discovery? Nat Rev Drug Discov. 2007;6:273-286.

8. Gwyther SJ. New imaging techniques in cancer management. Ann Oncol. 2005;16(suppl 2):ii63-ii70.

9. Rudin M, Weissleder R. Molecular imaging in drug discovery and development. Nat Rev Drug Discov. 2003;2:123-131.

10. Mankoff DA. A definition of molecular imaging. J Nucl Med. 2007;48(6):18N, $21 \mathrm{~N}$

11. Massoud TF, Gambhir SS. Molecular imaging in living subjects: seeing fundamental biological processes in a new light. Genes Dev. 2003;17:545-580.

12. Beyer T, Townsend DW, Brun T, et al. A combined PET/CT scanner for clinical oncology. J Nucl Med. 2000;41:1369-1379.

13. Even-Sapir E, Lerman H, Lievshitz G, et al. Lymphoscintigraphy for sentinel node mapping using a hybrid SPECT/CT system. J Nucl Med. 2003;44:14131420.

14. Catana C, Wu Y, Judenhofer MS, Qi J, Pichler BJ, Cherry SR. Simultaneous acquisition of multislice PET and MR images: initial results with a MRcompatible PET scanner. J Nucl Med. 2006;47:1968-1976.

15. Cai W, Rao J, Gambhir SS, Chen X. How molecular imaging is speeding up anti-angiogenic drug development. Mol Cancer Ther. 2006;5:2624-2633.

16. Iagaru A, Chen X, Gambhir SS. Molecular imaging can accelerate antiangiogenic drug development and testing. Nat Clin Pract Oncol. 2007;4: $556-557$.

17. Ferrara N. The role of VEGF in the regulation of physiological and pathological angiogenesis. EXS. 2005;94:209-231.

18. Cai W, Chen X. Multimodality imaging of vascular endothelial growth factor and vascular endothelial growth factor receptor expression. Front Biosci. 2007; 12:4267-4279.

19. Ferrara N. Vascular endothelial growth factor: basic science and clinical progress. Endocr Rev. 2004;25:581-611.

20. Hicklin DJ, Ellis LM. Role of the vascular endothelial growth factor pathway in tumor growth and angiogenesis. J Clin Oncol. 2005;23:1011-1027.

21. Sun J, Wang DA, Jain RK, et al. Inhibiting angiogenesis and tumorigenesis by a synthetic molecule that blocks binding of both VEGF and PDGF to their receptors. Oncogene. 2005;24:4701-4709.

22. Watanabe H, Mamelak AJ, Wang B, et al. Anti-vascular endothelial growth factor receptor-2 (Flk-1/KDR) antibody suppresses contact hypersensitivity. Exp Dermatol. 2004;13:671-681.

23. Prewett M, Huber J, Li Y, et al. Antivascular endothelial growth factor receptor (fetal liver kinase 1) monoclonal antibody inhibits tumor angiogenesis and growth of several mouse and human tumors. Cancer Res. 1999;59:5209-5218.

24. Ciardiello F, Caputo R, Damiano V, et al. Antitumor effects of ZD6474, a small molecule vascular endothelial growth factor receptor tyrosine kinase inhibitor, with additional activity against epidermal growth factor receptor tyrosine kinase. Clin Cancer Res. 2003;9:1546-1556. 
25. Wedge SR, Ogilvie DJ, Dukes M, et al. ZD4190: an orally active inhibitor of vascular endothelial growth factor signaling with broad-spectrum antitumor efficacy. Cancer Res. 2000;60:970-975.

26. Wood JM, Bold G, Buchdunger E, et al. PTK787/ZK 222584, a novel and potent inhibitor of vascular endothelial growth factor receptor tyrosine kinases, impairs vascular endothelial growth factor-induced responses and tumor growth after oral administration. Cancer Res. 2000;60:2178-2189.

27. Middleton G, Lapka DV. Bevacizumab (Avastin). Clin J Oncol Nurs. 2004; 8:666-669.

28. Eskens FA. Angiogenesis inhibitors in clinical development: where are we now and where are we going? Br J Cancer. 2004;90:1-7.

29. Ferrara N, Hillan KJ, Gerber HP, Novotny W. Discovery and development of bevacizumab, an anti-VEGF antibody for treating cancer. Nat Rev Drug Discov. 2004;3:391-400.

30. Peremans K, Cornelissen B, Van Den Bossche B, Audenaert K, Van de Wiele C. A review of small animal imaging planar and pinhole SPECT gamma camera imaging. Vet Radiol Ultrasound. 2005;46:162-170.

31. Li S, Peck-Radosavljevic M, Koller E, et al. Characterization of ${ }^{123}$ I-vascular endothelial growth factor-binding sites expressed on human tumour cells: possible implication for tumour scintigraphy. Int J Cancer. 2001;91:789-796.

32. Li S, Peck-Radosavljevic M, Kienast O, et al. Imaging gastrointestinal tumours using vascular endothelial growth factor-165 $\left(\mathrm{VEGF}_{165}\right)$ receptor scintigraphy. Ann Oncol. 2003;14:1274-1277.

33. Li S, Peck-Radosavljevic M, Kienast O, et al. Iodine-123-vascular endothelial growth factor-165 ( $\left.{ }^{123} \mathrm{I}_{-} \mathrm{VEGF}_{165}\right)$ : biodistribution, safety and radiation dosimetry in patients with pancreatic carcinoma. Q J Nucl Med Mol Imaging. 2004; 48:198-206.

34. Cornelissen B, Oltenfreiter R, Kersemans V, et al. In vitro and in vivo evaluation of $\left[{ }^{123} \mathrm{I}\right]-\mathrm{VEGF}_{165}$ as a potential tumor marker. Nucl Med Biol. 2005; 32:431-436.

35. Yoshimoto M, Kinuya S, Kawashima A, Nishii R, Yokoyama K, Kawai K. Radioiodinated VEGF to image tumor angiogenesis in a LS180 tumor xenograft model. Nucl Med Biol. 2006;33:963-969.

36. Blankenberg FG, Mandl S, Cao YA, et al. Tumor imaging using a standardized radiolabeled adapter protein docked to vascular endothelial growth factor. J Nucl Med. 2004;45:1373-1380.

37. Backer MV, Levashova Z, Patel V, et al. Molecular imaging of VEGF receptors in angiogenic vasculature with single-chain VEGF-based probes. Nat Med. 2007;13:504-509.

38. Blankenberg FG, Backer MV, Levashova Z, Patel V, Backer JM. In vivo tumor angiogenesis imaging with site-specific labeled ${ }^{99 \mathrm{~m} T c-H Y N I C-V E G F . ~ E u r ~} J$ Nucl Med Mol Imaging. 2006;33:841-848.

39. Chan C, Sandhu J, Guha A, et al. A human transferrin-vascular endothelial growth factor (hnTf-VEGF) fusion protein containing an integrated binding site for ${ }^{111}$ In for imaging tumor angiogenesis. J Nucl Med. 2005;46:1745-1752.

40. Chatziioannou AF. Instrumentation for molecular imaging in preclinical research: Micro-PET and Micro-SPECT. Proc Am Thorac Soc. 2005;2:510$511,533-536$.

41. Townsend DW, Beyer T. A combined PET/CT scanner: the path to true image fusion. Br J Radiol. 2002;75(special number):S24-S30.

42. Collingridge DR, Carroll VA, Glaser M, et al. The development of $\left[{ }^{124} \mathrm{I}\right]$ iodinated-VG76e: a novel tracer for imaging vascular endothelial growth factor in vivo using positron emission tomography. Cancer Res. 2002;62:5912-5919.

43. Jayson GC, Zweit J, Jackson A, et al. Molecular imaging and biological evaluation of HuMV833 anti-VEGF antibody: implications for trial design of antiangiogenic antibodies. J Natl Cancer Inst. 2002;94:1484-1493.

44. Nagengast WB, de Vries EG, Hospers GA, et al. In vivo VEGF imaging with radiolabeled bevacizumab in a human ovarian tumor xenograft. $J$ Nucl Med. 2007;48:1313-1319.

45. Cai W, Chen K, He L, Cao Q, Koong A, Chen X. Quantitative PET of EGFR expression in xenograft-bearing mice using ${ }^{64} \mathrm{Cu}$-labeled cetuximab, a chimeric anti-EGFR monoclonal antibody. Eur J Nucl Med Mol Imaging. 2007;34:850858.

46. Cai W, Ebrahimnejad A, Chen K, et al. Quantitative radioimmunoPET imaging of EphA2 in tumour-bearing mice. Eur J Nucl Med Mol Imaging. 2007;34: 2024-2036.

47. Cai $\mathrm{W}, \mathrm{Wu} \mathrm{Y}$, Chen $\mathrm{K}, \mathrm{Cao} \mathrm{Q}$, Tice DA, Chen $\mathrm{X}$. In vitro and in vivo characterization of ${ }^{64} \mathrm{Cu}$-labeled Abegrin ${ }^{\mathrm{TM}}$, a humanized monoclonal antibody against integrin $\alpha_{\mathrm{v}} \beta_{3}$. Cancer Res. 2006;66:9673-9681.

48. Cai W, Chen K, Mohamedali KA, et al. PET of vascular endothelial growth factor receptor expression. J Nucl Med. 2006;47:2048-2056.

49. Hsu AR, Cai W, Veeravagu A, et al. Multimodality molecular imaging of glioblastoma growth inhibition with vasculature-targeting fusion toxin VEGF $_{121} /$ rGel. J Nucl Med. 2007;48:445-454.
50. Simon M, Rockl W, Hornig C, et al. Receptors of vascular endothelial growth factor/vascular permeability factor (VEGF/VPF) in fetal and adult human kidney: localization and [125I]VEGF binding sites. J Am Soc Nephrol. 1998; 9:1032-1044.

51. Underiner TL, Ruggeri B, Gingrich DE. Development of vascular endothelial growth factor receptor (VEGFR) kinase inhibitors as anti-angiogenic agents in cancer therapy. Curr Med Chem. 2004;11:731-745.

52. Keyt BA, Nguyen HV, Berleau LT, et al. Identification of vascular endothelial growth factor determinants for binding KDR and FLT-1 receptors: generation of receptor-selective VEGF variants by site-directed mutagenesis. J Biol Chem. 1996;271:5638-5646.

53. Wang H, Cai W, Chen K, et al. A new PET tracer specific for vascular endothelial growth factor receptor 2. Eur J Nucl Med Mol Imaging. 2007; 34:2001-2010.

54. Choyke PL, Dwyer AJ, Knopp MV. Functional tumor imaging with dynamic contrast-enhanced magnetic resonance imaging. J Magn Reson Imaging. 2003;17:509-520.

55. O'Connor JP, Jackson A, Parker GJ, Jayson GC. DCE-MRI biomarkers in the clinical evaluation of antiangiogenic and vascular disrupting agents. $\mathrm{Br} \mathrm{J}$ Cancer: 2007;96:189-195.

56. Matsubayashi R, Matsuo Y, Edakuni G, Satoh T, Tokunaga O, Kudo S. Breast masses with peripheral rim enhancement on dynamic contrast-enhanced MR images: correlation of MR findings with histologic features and expression of growth factors. Radiology. 2000;217:841-848.

57. Hoang BH, Dyke JP, Koutcher JA, et al. VEGF expression in osteosarcoma correlates with vascular permeability by dynamic MRI. Clin Orthop Relat Res. 2004;426:32-38.

58. Knopp MV, Weiss E, Sinn HP, et al. Pathophysiologic basis of contrast enhancement in breast tumors. J Magn Reson Imaging. 1999;10:260-266.

59. Su MY, Cheung YC, Fruehauf JP, et al. Correlation of dynamic contrast enhancement MRI parameters with microvessel density and VEGF for assessment of angiogenesis in breast cancer. J Magn Reson Imaging. 2003; 18:467-477.

60. Hawighorst H, Knapstein PG, Knopp MV, et al. Uterine cervical carcinoma: comparison of standard and pharmacokinetic analysis of time-intensity curves for assessment of tumor angiogenesis and patient survival. Cancer Res. 1998; 58:3598-3602.

61. Wang B, Gao ZQ, Yan X. Correlative study of angiogenesis and dynamic contrast-enhanced magnetic resonance imaging features of hepatocellular carcinoma. Acta Radiol. 2005;46:353-358.

62. Sosnovik DE, Weissleder R. Emerging concepts in molecular MRI. Curr Opin Biotechnol. 2007;18:4-10.

63. Bloch SH, Dayton PA, Ferrara KW. Targeted imaging using ultrasound contrast agents: progress and opportunities for clinical and research applications. IEEE Eng Med Biol Mag. 2004;23:18-29.

64. Wink MH, Wijkstra H, De La Rosette JJ, Grimbergen CA. Ultrasound imaging and contrast agents: a safe alternative to MRI? Minim Invasive Ther Allied Technol. 2006;15:93-100.

65. Liang HD, Blomley MJ. The role of ultrasound in molecular imaging. $\mathrm{Br} \mathrm{J}$ Radiol. 2003;76(special number 2):S140-S150.

66. Drevs J, Hofmann I, Hugenschmidt H, et al. Effects of PTK787/ZK 222584, a specific inhibitor of vascular endothelial growth factor receptor tyrosine kinases, on primary tumor, metastasis, vessel density, and blood flow in a murine renal cell carcinoma model. Cancer Res. 2000;60:4819-4824.

67. Forsberg F, Dicker AP, Thakur ML, et al. Comparing contrast-enhanced ultrasound to immunohistochemical markers of angiogenesis in a human melanoma xenograft model: preliminary results. Ultrasound Med Biol. 2002; 28:445-451.

68. Forsberg F, Ro RJ, Potoczek M, et al. Assessment of angiogenesis: implications for ultrasound imaging. Ultrasonics. 2004;42:325-330.

69. Cheung AM, Brown AS, Cucevic V, et al. Detecting vascular changes in tumour xenografts using micro-ultrasound and micro-CT following treatment with VEGFR-2 blocking antibodies. Ultrasound Med Biol. 2007;33:1259-1268.

70. Korpanty G, Carbon JG, Grayburn PA, Fleming JB, Brekken RA. Monitoring response to anticancer therapy by targeting microbubbles to tumor vasculature. Clin Cancer Res. 2007;13:323-330.

71. Korpanty G, Grayburn PA, Shohet RV, Brekken RA. Targeting vascular endothelium with avidin microbubbles. Ultrasound Med Biol. 2005;31:1279-1283.

72. Willmann JK, Paulmurugan R, Chen K, et al. US imaging of tumor angiogenesis with microbubbles targeted to vascular endothelial growth factor receptor type 2 in mice. Radiology. 2008;246:508-518.

73. Shohet RV, Chen S, Zhou YT, et al. Echocardiographic destruction of albumin microbubbles directs gene delivery to the myocardium. Circulation. 2000; 101:2554-2556. 
74. Weissleder R, Mahmood U. Molecular imaging. Radiology. 2001;219:316-333.

75. Backer MV, Gaynutdinov TI, Patel V, et al. Vascular endothelial growth factor selectively targets boronated dendrimers to tumor vasculature. Mol Cancer Ther. 2005;4:1423-1429.

76. Backer MV, Patel V, Jehning BT, Backer JM. Self-assembled "dock and lock" system for linking payloads to targeting proteins. Bioconjug Chem. 2006;17: 912-919.

77. Licha K, Riefke B, Ntziachristos V, Becker A, Chance B, Semmler W. Hydrophilic cyanine dyes as contrast agents for near-infrared tumor imaging: synthesis, photophysical properties and spectroscopic in vivo characterization. Photochem Photobiol. 2000;72:392-398.

78. Wu Y, Cai W, Chen X. Near-infrared fluorescence imaging of tumor integrin $\alpha_{\mathrm{v}} \beta_{3}$ expression with Cy7-labeled RGD multimers. Mol Imaging Biol. 2006; $8: 226-236$

79. Lin PC. Optical imaging and tumor angiogenesis. J Cell Biochem. 2003; 90:484-491.

80. Cai W, Hsu AR, Li ZB, Chen X. Are quantum dots ready for in vivo imaging in human subjects? Nanoscale Res Lett. 2007;2:265-281.

81. Frangioni JV. In vivo near-infrared fluorescence imaging. Curr Opin Chem Biol. 2003;7:626-634.

82. Cai $\mathrm{W}$, Zhang $\mathrm{X}, \mathrm{Wu} \mathrm{Y}$, Chen $\mathrm{X}$. A thiol-reactive ${ }^{18} \mathrm{~F}$-labeling agent, $N$-[2(4- ${ }^{18}$ F-fluorobenzamido)ethyl]maleimide, and synthesis of RGD peptide-based tracer for PET imaging of $\alpha_{v} \beta_{3}$ integrin expression. J Nucl Med. 2006; 47:1172-1180.

83. Cai W, Olafsen $T$, Zhang $X$, et al. PET imaging of colorectal cancer in xenograft-bearing mice by use of an ${ }^{18} \mathrm{~F}$-labeled $\mathrm{T} 84.66$ anti-carcinoembryonic antigen diabody. J Nucl Med. 2007;48:304-310.

84. Michalet X, Pinaud FF, Bentolila LA, et al. Quantum dots for live cells, in vivo imaging, and diagnostics. Science. 2005;307:538-544.

85. Jares-Erijman EA, Jovin TM. Imaging molecular interactions in living cells by FRET microscopy. Curr Opin Chem Biol. 2006;10:409-416.

86. Jares-Erijman EA, Jovin TM. FRET imaging. Nat Biotechnol. 2003;21:13871395.

87. Villalobos V, Naik S, Piwnica-Worms D. Current state of imaging proteinprotein interactions in vivo with genetically encoded reporters. Annu Rev Biomed Eng. 2007;9:321-349.

88. Hynes RO. Integrins: bidirectional, allosteric signaling machines. Cell. 2002; 110:673-687.

89. Hood JD, Cheresh DA. Role of integrins in cell invasion and migration. Nat Rev Cancer. 2002;2:91-100.

90. Xiong JP, Stehle T, Zhang R, et al. Crystal structure of the extracellular segment of integrin $\alpha_{\mathrm{v}} \beta_{3}$ in complex with an Arg-Gly-Asp ligand. Science. 2002;296:151-155.

91. Cai W, Gambhir SS, Chen X. Multimodality tumor imaging targeting integrin $\alpha_{\mathrm{v}} \beta_{3}$. Biotechniques. 2005;39(suppl):S6-S17.

92. Haubner R. $\alpha_{\mathrm{v}} \beta_{3}$-Integrin imaging: a new approach to characterise angiogenesis? Eur J Nucl Med Mol Imaging. 2006;33(suppl 13):54-63.

93. Liu S. Radiolabeled multimeric cyclic RGD peptides as integrin $\alpha_{\mathrm{v}} \beta_{3}$ targeted radiotracers for tumor imaging. Mol Pharm. 2006;3:472-487.

94. Chen X, Conti PS, Moats RA. In vivo near-infrared fluorescence imaging of integrin $\alpha_{\mathrm{v}} \beta_{3}$ in brain tumor xenografts. Cancer Res. 2004;64:8009-8014.

95. Chen X, Hou Y, Tohme M, et al. Pegylated Arg-Gly-Asp peptide: ${ }^{64} \mathrm{Cu}$ labeling and PET imaging of brain tumor $\alpha_{\mathrm{v}} \beta_{3}$-integrin expression. J Nucl Med. 2004; 45:1776-1783.

96. Haubner R, Weber WA, Beer AJ, et al. Noninvasive visualization of the activated $\alpha_{\mathrm{v}} \beta_{3}$ integrin in cancer patients by positron emission tomography and $\left[{ }^{18}\right.$ F $]$ galacto-RGD. PLoS Med. 2005;2:e70.

97. Haubner R, Wester H-J, Weber WA, et al. Noninvasive imaging of $\alpha_{\mathrm{v}} \beta_{3}$ integrin expression using ${ }^{18} \mathrm{~F}$-labeled RGD-containing glycopeptide and positron emission tomography. Cancer Res. 2001;61:1781-1785.

98. Chen X, Park R, Hou Y, et al. MicroPET imaging of brain tumor angiogenesis with ${ }^{18}$ F-labeled PEGylated RGD peptide. Eur J Nucl Med Mol Imaging. 2004;31:1081-1089.

99. Janssen ML, Oyen WJ, Dijkgraaf I, et al. Tumor targeting with radiolabeled $\alpha_{v} \beta_{3}$ integrin binding peptides in a nude mouse model. Cancer Res. 2002; 62:6146-6151.

100. Chen X, Park R, Shahinian AH, et al. ${ }^{18}$ F-Labeled RGD peptide: initial evaluation for imaging brain tumor angiogenesis. Nucl Med Biol. 2004;31:179-189.

101. Chen X, Park R, Tohme M, Shahinian AH, Bading JR, Conti PS. MicroPET and autoradiographic imaging of breast cancer $\alpha_{\mathrm{v}}$-integrin expression using ${ }^{18} \mathrm{~F}$ and ${ }^{64} \mathrm{Cu}$-labeled RGD peptide. Bioconjug Chem. 2004;15:41-49.

102. Wu Y, Zhang X, Xiong Z, et al. microPET imaging of glioma integrin $\alpha_{\mathrm{v}} \beta_{3}$ expression using ${ }^{64} \mathrm{Cu}$-labeled tetrameric RGD peptide. J Nucl Med. 2005; 46:1707-1718.
103. Zhang $\mathrm{X}$, Xiong $\mathrm{Z}, \mathrm{Wu} \mathrm{Y}$, et al. Quantitative PET imaging of tumor integrin $\alpha_{\mathrm{v}} \beta_{3}$ expression with ${ }^{18}$ F-FRGD2. J Nucl Med. 2006;47:113-121.

104. Chen X, Sievers E, Hou Y, et al. Integrin $\alpha_{\mathrm{v}} \beta_{3}$-targeted imaging of lung cancer. Neoplasia. 2005;7:271-279.

105. Chen X, Tohme M, Park R, Hou Y, Bading JR, Conti PS. Micro-PET imaging of $\alpha_{\mathrm{v}} \beta_{3}$-integrin expression with ${ }^{18} \mathrm{~F}$-labeled dimeric RGD peptide. Mol Imaging. 2004;3:96-104.

106. Cheng Z, Wu Y, Xiong Z, Gambhir SS, Chen X. Near-infrared fluorescent RGD peptides for optical imaging of integrin $\alpha_{\mathrm{v}} \beta_{3}$ expression in living mice. Bioconjug Chem. 2005;16:1433-1441.

107. Wu Z, Li ZB, Cai W, et al. ${ }^{18} \mathrm{~F}$-Labeled mini-PEG spacered RGD dimer $\left({ }^{18} \mathrm{~F}-\right.$ FPRGD2): synthesis and microPET imaging of $\alpha_{\mathrm{v}} \beta_{3}$ integrin expression. Eur $J$ Nucl Med Mol Imaging. May 5, 2007 [Epub ahead of print].

108. Li ZB, Cai W, Cao Q, et al. ${ }^{64} \mathrm{Cu}$-Labeled tetrameric and octameric RGD peptides for small-animal PET of tumor $\alpha_{\mathrm{v}} \beta_{3}$ integrin expression. J Nucl Med. 2007;48:1162-1171.

109. Liu S, Hsieh WY, Jiang Y, et al. Evaluation of a ${ }^{99 m} \mathrm{Tc}$-labeled cyclic RGD tetramer for noninvasive imaging integrin $\alpha_{v} \beta_{3}$-positive breast cancer. Bioconjug Chem. 2007; 18:438-446.

110. Wu Z, Li ZB, Chen K, et al. microPET of tumor integrin $\alpha_{\mathrm{v}} \beta_{3}$ expression using ${ }^{18} \mathrm{~F}$-labeled PEGylated tetrameric RGD peptide ( $\left.{ }^{18} \mathrm{~F}-\mathrm{FPRGD} 4\right) . \mathrm{J}$ Nucl Med. 2007;48:1536-1544.

111. Hu G, Lijowski M, Zhang $H$, et al. Imaging of $\mathrm{Vx}-2$ rabbit tumors with $\alpha_{\mathrm{v}} \beta_{3^{-}}$ integrin-targeted ${ }^{111}$ In nanoparticles. Int J Cancer. 2007;120:1951-1957.

112. Smith AE. Viral vectors in gene therapy. Annu Rev Microbiol. 1995;49:807838 .

113. Nicklin SA, Baker AH. Tropism-modified adenoviral and adeno-associated viral vectors for gene therapy. Curr Gene Ther. 2002;2:273-293.

114. Mizuguchi H, Hayakawa T. Targeted adenovirus vectors. Hum Gene Ther. 2004; 15:1034-1044.

115. Glasgow JN, Everts M, Curiel DT. Transductional targeting of adenovirus vectors for gene therapy. Cancer Gene Ther. 2006;13:830-844.

116. Xiong Z, Cheng Z, Zhang X, et al. Imaging chemically modified adenovirus for targeting tumors expressing integrin $\alpha_{\mathrm{v}} \beta_{3}$ in living mice with mutant herpes simplex virus type 1 thymidine kinase PET reporter gene. J Nucl Med. 2006; 47:130-139.

117. Yaghoubi S, Barrio JR, Dahlbom M, et al. Human pharmacokinetic and dosimetry studies of $\left[{ }^{18} \mathrm{~F}\right] \mathrm{FHBG}$ : a reporter probe for imaging herpes simplex virus type-1 thymidine kinase reporter gene expression. J Nucl Med. 2001; 42:1225-1234.

118. Alauddin MM, Conti PS. Synthesis and preliminary evaluation of 9-(4-[ $\left.{ }^{18} \mathrm{~F}\right]-$ fluoro-3-hydroxymethylbutyl)guanine ([ $\left.\left.{ }^{18} \mathrm{~F}\right] \mathrm{FHBG}\right)$ : a new potential imaging agent for viral infection and gene therapy using PET. Nucl Med Biol. 1998; 25:175-180.

119. Niu G, Xiong Z, Cheng Z, et al. In vivo bioluminescence tumor imaging of RGD peptide-modified adenoviral vector encoding firefly luciferase reporter gene. Mol Imaging Biol. 2007;9:126-134.

120. Balasubramanian K, Burghard M. Chemically functionalized carbon nanotubes. Small. 2005;1:180-192.

121. Lacerda L, Bianco A, Prato M, Kostarelos K. Carbon nanotubes as nanomedicines: from toxicology to pharmacology. Adv Drug Deliv Rev. 2006;58:1460-1470.

122. Liu Z, Cai W, He L, et al. In vivo biodistribution and highly efficient tumour targeting of carbon nanotubes in mice. Nat Nanotechnol. 2007;2:47-52.

123. Singh R, Pantarotto D, Lacerda L, et al. Tissue biodistribution and blood clearance rates of intravenously administered carbon nanotube radiotracers. Proc Natl Acad Sci USA. 2006;103:3357-3362.

124. McDevitt MR, Chattopadhyay D, Kappel BJ, et al. Tumor targeting with antibody-functionalized, radiolabeled carbon nanotubes. J Nucl Med. 2007; 48:1180-1189.

125. Caliceti P, Veronese FM. Pharmacokinetic and biodistribution properties of poly(ethylene glycol)-protein conjugates. Adv Drug Deliv Rev. 2003;55: 1261-1277.

126. Wu AM, Senter PD. Arming antibodies: prospects and challenges for immunoconjugates. Nat Biotechnol. 2005;23:1137-1146.

127. Pathak AP, Gimi B, Glunde K, Ackerstaff E, Artemov D, Bhujwalla ZM. Molecular and functional imaging of cancer: advances in MRI and MRS. Methods Enzymol. 2004;386:3-60.

128. Zhang Z, Nair SA, McMurry TJ. Gadolinium meets medicinal chemistry: MRI contrast agent development. Curr Med Chem. 2005;12:751-778.

129. Pautler RG, Fraser SE. The year(s) of the contrast agent: micro-MRI in the new millennium. Curr Opin Immunol. 2003;15:385-392.

130. de Roos A, Doornbos J, Baleriaux D, Bloem HL, Falke TH. Clinical applications of gadolinium-DTPA in MRI. Magn Reson Annu. 1988:113-145. 
131. Thorek DL, Chen AK, Czupryna J, Tsourkas A. Superparamagnetic iron oxide nanoparticle probes for molecular imaging. Ann Biomed Eng. 2006; 34:23-38.

132. Sipkins DA, Cheresh DA, Kazemi MR, Nevin LM, Bednarski MD, Li KC. Detection of tumor angiogenesis in vivo by $\alpha_{\mathrm{v}} \beta_{3}$-targeted magnetic resonance imaging. Nat Med. 1998;4:623-626.

133. Winter PM, Caruthers SD, Kassner A, et al. Molecular imaging of angiogenesis in nascent $\mathrm{Vx}$-2 rabbit tumors using a novel $\alpha_{\mathrm{v}} \beta_{3}$-targeted nanoparticle and 1.5 tesla magnetic resonance imaging. Cancer Res. 2003;63:5838-5843.

134. Schmieder AH, Winter PM, Caruthers SD, et al. Molecular MR imaging of melanoma angiogenesis with $\alpha_{\mathrm{v}} \beta_{3}$-targeted paramagnetic nanoparticles. Magn Reson Med. 2005;53:621-627.

135. Zhang C, Jugold M, Woenne EC, et al. Specific targeting of tumor angiogenesis by RGD-conjugated ultrasmall superparamagnetic iron oxide particles using a clinical 1.5-T magnetic resonance scanner. Cancer Res. 2007;67:1555-1562.

136. Golman K, Zandt RI, Lerche M, Pehrson R, Ardenkjaer-Larsen JH. Metabolic imaging by hyperpolarized ${ }^{13} \mathrm{C}$ magnetic resonance imaging for in vivo tumor diagnosis. Cancer Res. 2006;66:10855-10860.

137. Zhang S, Merritt M, Woessner DE, Lenkinski RE, Sherry AD. PARACEST agents: modulating MRI contrast via water proton exchange. Acc Chem Res. 2003; 36:783-790.

138. Kaufmann BA, Lindner JR. Molecular imaging with targeted contrast ultrasound. Curr Opin Biotechnol. 2007;18:11-16.

139. Ellegala DB, Leong-Poi H, Carpenter JE, et al. Imaging tumor angiogenesis with contrast ultrasound and microbubbles targeted to $\alpha_{\mathrm{v}} \beta_{3}$. Circulation. 2003; 108:336-341.

140. Kumar CC, Nie H, Rogers CP, et al. Biochemical characterization of the binding of echistatin to integrin $\alpha_{\mathrm{v}} \beta_{3}$ receptor. J Pharmacol Exp Ther. 1997;283:843-853.

141. Hughes MS, Marsh JN, Zhang H, et al. Characterization of digital waveforms using thermodynamic analogs: detection of contrast-targeted tissue in vivo. IEEE Trans Ultrason Ferroelectr Freq Control. 2006;53:1609-1616.

142. Medintz IL, Uyeda HT, Goldman ER, Mattoussi H. Quantum dot bioconjugates for imaging, labelling and sensing. Nat Mater. 2005;4:435-446.

143. Cai W, Shin DW, Chen K, et al. Peptide-labeled near-infrared quantum dots for imaging tumor vasculature in living subjects. Nano Lett. 2006;6:669-676.

144. Levenson RM. Spectral imaging and pathology: seeing more. Lab Med. 2004; 35:244-251.

145. Mansfield JR, Gossage KW, Hoyt CC, Levenson RM. Autofluorescence removal, multiplexing, and automated analysis methods for in-vivo fluorescence imaging. J Biomed Opt. 2005;10:41207.

146. Kim S, Lim YT, Soltesz EG, et al. Near-infrared fluorescent type II quantum dots for sentinel lymph node mapping. Nat Biotechnol. 2004;22:93-97.
147. Zimmer JP, Kim SW, Ohnishi S, Tanaka E, Frangioni JV, Bawendi MG. Size series of small indium arsenide-zinc selenide core-shell nanocrystals and their application to in vivo imaging. J Am Chem Soc. 2006;128:2526-2527.

148. Pradhan N, Battaglia DM, Liu Y, Peng X. Efficient, stable, small, and watersoluble doped $\mathrm{ZnSe}$ nanocrystal emitters as non-cadmium biomedical labels. Nano Lett. 2007;7:312-317.

149. Kim SW, Zimmer JP, Ohnishi S, Tracy JB, Frangioni JV, Bawendi MG. Engineering InAs $\mathrm{P}_{1-\mathrm{x}} / \mathrm{InP} / \mathrm{ZnSe}$ III-V alloyed core/shell quantum dots for the near-infrared. J Am Chem Soc. 2005;127:10526-10532.

150. Pradhan N, Peng X. Efficient and color-tunable Mn-doped ZnSe nanocrystal emitters: control of optical performance via greener synthetic chemistry. $J \mathrm{Am}$ Chem Soc. 2007;129:3339-3347.

151. Mulder WJ, Koole R, Brandwijk RJ, et al. Quantum dots with a paramagnetic coating as a bimodal molecular imaging probe. Nano Lett. 2006;6:1-6.

152. Selvan ST, Patra PK, Ang CY, Ying JY. Synthesis of silica-coated semiconductor and magnetic quantum dots and their use in the imaging of live cells. Angew Chem Int Ed Engl. 2007;46:2448-2452.

153. Mulder WJ, Strijkers GJ, Habets JW, et al. MR molecular imaging and fluorescence microscopy for identification of activated tumor endothelium using a bimodal lipidic nanoparticle. FASEB J. 2005;19:2008-2010.

154. Cai W, Chen K, Li ZB, Gambhir SS, Chen X. Dual-function probe for PET and near-infrared fluorescence imaging of tumor vasculature. $J$ Nucl Med. 2007;48:1862-1870.

155. Kirchner C, Liedl T, Kudera S, et al. Cytotoxicity of colloidal CdSe and CdSe/ ZnS nanoparticles. Nano Lett. 2005;5:331-338.

156. Derfus AM, Chan WCW, Bhatia SN. Probing the cytotoxicity of semiconductor quantum dots. Nano Lett. 2004;4:11-18.

157. Cherry SR, Shao Y, Silverman RW, et al. MicroPET: a high resolution PET scanner for imaging small animals. IEEE Trans Nucl Sci. 1997;44:11611166.

158. Chatziioannou AF, Cherry SR, Shao Y, et al. Performance evaluation of microPET: a high-resolution lutetium oxyorthosilicate PET scanner for animal imaging. J Nucl Med. 1999;40:1164-1175.

159. De S, Razorenova O, McCabe NP, O'Toole T, Qin J, Byzova TV. VEGFintegrin interplay controls tumor growth and vascularization. Proc Natl Acad Sci USA. 2005;102:7589-7594.

160. Fonsatti E, Altomonte M, Nicotra MR, Natali PG, Maio M. Endoglin (CD105): a powerful therapeutic target on tumor-associated angiogenetic blood vessels. Oncogene. 2003;22:6557-6563.

161. Cai W, Chen X. Nanoplatforms for targeted molecular imaging in living subjects. Small. 2007;3:1840-1854. 